\title{
QUEEN'S
UNIVERSITY
BELFAST
}

\section{Thin-ply polymer composite materials: A review}

Arteiro, A., Furtado, C., Catalanotti, G., Linde, P., \& Camanho, P. P. (2020). Thin-ply polymer composite materials: A review. Composites Part A: Applied Science and Manufacturing, 132, [105777]. https://doi.org/10.1016/j.compositesa.2020.105777

\section{Published in:}

Composites Part A: Applied Science and Manufacturing

\section{Document Version:}

Peer reviewed version

\section{Queen's University Belfast - Research Portal:}

Link to publication record in Queen's University Belfast Research Portal

\section{Publisher rights}

Copyright 2020 Elsevier

This manuscript is distributed under a Creative Commons Attribution-NonCommercial-NoDerivs License

(https://creativecommons.org/licenses/by-nc-nd/4.0/), which permits distribution and reproduction for non-commercial purposes, provided the author and source are cited.

\section{General rights}

Copyright for the publications made accessible via the Queen's University Belfast Research Portal is retained by the author(s) and / or other copyright owners and it is a condition of accessing these publications that users recognise and abide by the legal requirements associated with these rights.

\section{Take down policy}

The Research Portal is Queen's institutional repository that provides access to Queen's research output. Every effort has been made to ensure that content in the Research Portal does not infringe any person's rights, or applicable UK laws. If you discover content in the Research Portal that you believe breaches copyright or violates any law, please contact openaccess@qub.ac.uk. 


\title{
Thin-ply polymer composite materials: a review
}

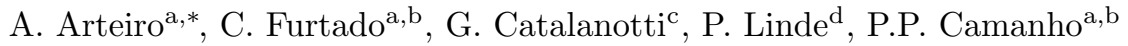 \\ ${ }^{a}$ DEMec, Faculdade de Engenharia, Universidade do Porto, Rua Dr. Roberto Frias, s/n, \\ 4200-465 Porto, Portugal \\ ${ }^{b}$ INEGI, Instituto de Ciência e Inovação em Engenharia Mecânica e Engenharia Industrial, \\ Rua Dr. Roberto Frias, 400, 4200-465 Porto, Portugal \\ ${ }^{c}$ Advanced Composites Research Group (ACRG), School of Mechanical and Aerospace \\ Engineering, Queen's University Belfast, Belfast BT9 5AH, UK \\ ${ }^{d}$ AIRBUS Operations GmbH, Kreetslag 10, 21129 Hamburg, Germany
}

\begin{abstract}
The introduction of the spread-tow thin-ply technology enabled the development of composite plies as thin as $0.020 \mathrm{~mm}$. The availability of composite plies with a broader thickness range makes the understanding of the effects of ply thickness more pertinent than ever, therefore, a comprehensive literature review is presented in this paper. The micro-structural effects of ply thickness and ply uniformity on the mechanical response of unidirectional laminae is described. Then, the effect of ply thickness scaling on several aspects of the mechanical response of composite laminates is reviewed. Finally, the current state-of-art and recent developments in manufacturing, design and application of thin plies on novel engineered composite laminates are presented. This review demonstrates that thin plies not only bring improvements to the plain strengths and design flexibility of composite laminates, but can also enhance the performance of primary structural applications, namely those driven by residual strength and damage tolerance requirements. This can be achieved by either combining thin plies with existing material technologies, or through novel design principles. Moreover, it is shown that thin plies provide increased flexibility for multifunctional optimisation and for adoption of more efficient manufacturing technologies, with great potential gains in terms of weight savings and cost
\end{abstract}

\footnotetext{
*Corresponding author. Tel.: +351 220414049. Fax: +351 225081440

Email address: aarteiro@fe.up.pt (A. Arteiro)
} 
reduction during conceptual and detailed design and operation.

Keywords: A. Polymer-matrix composites (PMCs), B. Mechanical properties, E. Tow spreading

\section{Introduction}

Advanced tow spreading techniques are currently used to continuously and stably open thick fibre tows and obtain uniform plies significantly thinner than conventional plies [1-3]. A careful control of the tension in the tows (or yarns) allows to cost-effectively produce flat and straight plies with a dry ply thickness as low as $0.020 \mathrm{~mm}$ without damaging the filament fibres. The availability of such thin plies, with a ply thickness equal to or below $0.100 \mathrm{~mm}$, opens a broad range of new possibilities in composites design, but also new challenges in understanding how ply thickness will affect the mechanical response of composite laminates.

With the aim of understanding the main effects of ply thickness in advanced laminate design, a comprehensive literature review is presented in this paper. Firstly, the micro-structural effects arising from ply thickness on the mechanical response of unidirectional (UD) laminae are discussed. Then, the effect of ply thickness scaling on the mechanical response of multi-directional composite laminates is thoroughly described. Finally, the current state-of-art and recent developments on manufacturing and design of laminates with thin plies and on the application of thin plies in novel engineered composite laminates are presented.

\section{Ply thinness and ply uniformity: effect on UD composites}

\subsection{Intra-laminar material properties}

The increased uniformity of spread tows when compared with standard grade materials (Fig. 1) has motivated the study of the effect of ply thickness on the mechanical response of UD composites. The experimental characterisation 
at the lamina level performed by Amacher et al. [4] show that ply thickness has no significant effect on the elastic and strength properties of the UD laminae, except for longitudinal compression. In this case, thin-ply UD specimens show substantially higher strength (up to $20 \%$ higher on average [4]). This enhanced compressive strength is attributed to the more uniform micro-structure of spread-tow thin plies. Optical micrographs (Fig. 1) show that the microstructure of laminates made of thicker plies are fairly inhomogeneous, with large variations of the local fibre volume fraction and resin rich regions throughout the composite. This heterogeneous micro-structure causes early fibre microinstabilities that conduct to premature compressive failure of UD laminae [4]. As the ply thickness decreases, a better uniformity of the micro-structure is observed, consequently delaying fibre micro-instabilities.

When used in the weaving process of woven fabrics, spread tows not only contribute to an improved uniformity of the micro-structure [4], but also to a better uniformity of the woven architecture [5]. Due to the reduced fibre waviness and crimp angles, micro- and meso-instabilities in the fibre direction can be effectively delayed. Longitudinal compressive strength improvements of up to $18 \%$ have been reported for UD and multi-directional plain weave spreadtow fabric laminates just by reducing the tow areal weight [6].

\subsection{Inter-laminar material properties}

\subsubsection{Inter-laminar shear strength}

Micro-structural uniformity has also potential effects on the inter-laminar properties of composites. Not only the inter-laminar shear strength (ILSS) of UD laminates increases (in the range of 30\%), but also the coefficients of variation of the ILSS data decrease with decreasing ply thickness [7]. Both effects were attributed to the more uniform micro-structure and smaller interlaminar resin-rich regions of thin-ply laminates (Fig. 1) [4, 7]. 


\subsubsection{Inter-laminar fracture toughness}

The inter-laminar fracture of UD composites is often characterised by an apparent increase of the fracture toughness with crack extension, leading to a crack resistance curve (or $\mathcal{R}$-curve) type of response [8-11]. This can be attributed, among other phenomena, to fibre bridging $[10,11]$. The extremely uniform micro-structure of very thin plies means that the potential for large-scale fibre bridging in UD composites is reduced when compared with more heterogeneous grades - see Fig. 2. Consequently, a flatter $\mathcal{R}$-curve, characterised by a lower steady-state value of the fracture toughness, can be expected for crack propagation parallel to the fibres. These observations have been corroborated by experiments carried out by Frossard et al. [12] for mode I inter-laminar fracture. Conversely, the mode II fracture toughness is practically insensitive to ply thickness [13], attributed to the minor role of dissipative mechanisms such as fibre bridging in the mode II component of the fracture toughness.

\subsection{Discussion}

It is apparent that the ply uniformity resulting from ply thinness has a strong beneficial effect on the longitudinal compressive strength and ILSS of UD composites. The enhanced longitudinal compressive strength can be considered one of the main contributors to the improved compressive plain strength of multi-directional laminates with thin plies $[6,14,15]$. However, the enhanced ILSS measured from UD coupons is not expected to have a major role on the ILSS of multi-directional laminates, since the effect of ply thickness on the inter-laminar stress distribution [7] is considered the dominant effect on the improved inter-laminar shear performance of multi-directional thin-ply laminates, overwhelming the micro-structural effects observed on UD laminates. For example, Kalfon-Cohen et al. [16] tested blocked (thick baseline) and dispersed (thin baseline) laminates manufactured from the same thin-ply composite system, obtaining higher ILSS on the thin baseline. Since the same thin-ply composite system was used in both laminates, no micro-structural effects should be expected, and the higher ILSS solely attributed to the effect of ply thickness on 
the inter-laminar stress distribution. Similar trends were obtained by Huang et al. [7] on multi-directional laminates manufactured from plies with different grades.

The same applies to the inter-laminar fracture toughness. Although bridging effects play a minor role on the inter-laminar fracture behaviour of UD thinply composites, leading to lower steady-state values of the fracture toughness when compared with conventional composites, in multi-directional laminates bridging phenomena is expected to be governed not by the uniformity of the micro-structure, but by the relative ply orientations and local stress state at the crack tip $[17,18]$ due to the fact that delaminations tend to propagate between plies with dissimilar orientation.

\section{Ply thickness scaling and its effect on composite laminates}

\subsection{Motivation}

In the past, several studies have addressed the effect of stacking sequence and ply thickness scaling on several aspects of the mechanical response of composite laminates [19-65]. These studies, which involved detailed experimental campaigns and/or analysis methods, have contributed to the understanding of the effect of ply thickness scaling on the nature of the damage mechanisms that cause laminate failure. However, the introduction of spread-tow thin plies makes this analysis more pertinent than ever, since the majority of the studies carried out in the past addressed ply thickness effects by means of ply scaling restricted to a minimum nominal ply thickness of $0.125 \mathrm{~mm}$, considerably above what can be obtained nowadays using tow spreading.

\subsection{Matrix cracking and in-situ effect}

\subsubsection{Constraining effects and in-situ strengths}

When embedded in a multi-directional laminate, the laminae whose fibre orientation is perpendicular to the loading direction generally develop matrix cracks at strains lower than the ultimate failure strain of the laminate (Fig. 3) 
$[66,67]$. These matrix cracks are responsible for the deterioration of the mechanical performance of the laminate, originating other damage modes (e.g. delamination), and creating pathways for chemicals and other substances [68].

Nevertheless, it is observed that the development of these matrix cracks (which define the actual strength of the transverse plies) occurs at applied stresses greater than the transverse strength measured in UD coupons; in fact, the actual strengths of transverse plies are not only higher than those measured in UD coupons, but they reportedly increase with decreasing ply thickness $[22,23,67,69]$. This is a deterministic size effect that occurs at the meso-scale, known as the in-situ effect. The neighbouring plies cause a constraining effect on the embedded ply, reducing the available elastic energy and delaying damage propagation in the matrix [4, 70-73]. Therefore, the ply strengths cannot be treated as intrinsic lamina properties [22, 74], but as in-situ properties that depend on the material and geometry of the laminate [23, 69, 75].

Several experimental studies in the literature show that the transverse tensile strength $\left(Y_{T}^{i s}\right)$ and the in-plane shear strength $\left(S_{L}^{i s}\right)$ of an embedded ply depend on the ply thickness [19-22, 24, 67, 74], on the orientation (or stiffness) of the adjacent plies $[22,74]$ (see Fig. 4), and on the ply location in the laminate $[40,76]$ (see Fig. 5). Indirect observations also show that the transverse shear strength $\left(S_{T}^{i s}\right)[16,77-80]$ and the transverse compressive strength $\left(Y_{C}^{i s}\right)[77,78,81]$ are in-situ properties too.

\subsubsection{In-situ transverse tensile strength}

From the late 1970s [19-21] to the late 1990s [22-24], experimental studies demonstrated that, when subjected to tensile loads, the transverse stress at the onset of matrix cracking in the $90^{\circ}$ laminae of glass and carbon fibre-reinforced polymer laminates changes with the thickness of the $90^{\circ}$ laminae and orientation of the adjacent plies. Experimental observations (e.g. Fig. 4) show that the transverse stress at the onset of matrix cracking increases with decreasing ply thickness and increasing stiffness of the adjacent laminae.

In the early 1980s, Herakovich [76] showed that the ultimate stress, the 
strain-to-failure and the toughness (measured as the area under the experimentally obtained stress-strain curves) of angle-ply laminates is higher when plies of the same orientation are dispersed through the laminate instead of blocked together due to a delay in matrix cracking that caused a strong change in the nature and sequence of the failure mechanisms (Fig. 6). More recently, Fuller and Wisnom [82] showed that matrix cracking parallel to the fibre direction in angle-ply laminates can be completely suppressed using a spread-tow thinply composite material, leading to a brittle type of net-section fibre-dominated failure mode (Fig. 6 - right).

Similar experimental observations reported severe degradation of the elastic properties with increasing transverse ply thickness in cross-ply laminates [70]. Thinner transverse plies are less susceptible to transverse crack initiation or propagation in the width direction, with edge cracks occurring at higher strain levels than in thicker $90^{\circ}$ plies of quasi-isotropic and cross-ply laminates [83]. In addition, the stress concentrations on the $0^{\circ}$ plies arising from transverse cracking in thick $90^{\circ}$ ply blocks can have a measurable effect on the strength of the $0^{\circ}$ ligaments and induce premature laminate failure too [44].

To predict these effects, progressive damage modelling formulated taking into account the in-situ effect revealed high efficiency, accurately capturing the reduction in the maximum failure load due to ply clustering in open-hole angleply and cross-ply laminates under tensile loading [84].

More recently, an increasing number of studies have demonstrated that the applied stress corresponding to the occurrence of the first transverse crack increases with decreasing ply thickness [34, 40, 68, 85-89], and that a reduction of the stiffness of the adjacent plies promotes transverse cracking $[68,85]$. The first studies addressing transverse cracking in spread-tow thin plies appeared in the early 2000s. Uniaxial tensile quasi-static tests on un-notched and open-hole multi-directional laminates $[4,6,28,30,66,80,90-94]$ showed that first-ply failure (FPF) is delayed nearly up to ultimate failure, as observed by free-edge observations, scanning electron microscope (SEM) visualisation, acoustic emission and/or digital image correlation (e.g. Fig. 7), and often supported by analysis 
[73, 91, 92]. In addition, much lower crack-opening displacements have been reported for transverse cracks in thin plies, which eventually never penetrate completely through the thickness [66]. In the case of quasi-isotropic laminates, this provides a safe space that is independent of the loading direction [95], since laminate failure will be fibre-dominated.

To clarify the nature of this size effect, Amacher et al. [4] tested thick-ply laminates produced from blocks of ten $30 \mathrm{~g} / \mathrm{m}^{2}$ thin plies and from individual $300 \mathrm{~g} / \mathrm{m}^{2}$ plies, and no substantial difference was found between these two laminates, demonstrating that the observed size effect was not related to changes in the material properties or micro-structure, but to the deterministic in-situ effect.

\subsubsection{In-situ in-plane shear strength}

Even though most of the studies addressing ply in-situ effects have been focused on matrix cracking in tension, this deterministic size effect was also observed under other loading scenarios. For example, experiments suggest a significant ply thickness effect on the in-plane shear strength of embedded plies $[74,96,97]$.

The relation between the in-situ in-plane shear strength and the ply thickness can be taken into account using fracture mechanics models and the intralaminar mode II fracture toughness [23, 69]. It is noted, though, that linear elastic fracture mechanics (LEFM) alone is not able to accurately predict the in-situ in-plane shear strength [69]; in this case, the nonlinear shear response typically observed in fibre-reinforced polymers (FRPs) must be included in the fracture mechanics model (Fig. 8).

\subsubsection{In-situ transverse shear and transverse compressive strengths}

Experimental studies have also shown that a substantial reduction in longitudinal compressive and transverse shear strengths can result from transverse cracking (see Ref. [22] for earlier references). Therefore, an in-situ effect on other matrix-dominated failure mechanisms is expected to exist, namely on transverse 
shear cracking, wedge transverse compressive fracture, and fibre kinking.

The application of three-dimensional (3D) phenomenological failure criteria has been proposed to estimate and take into account the in-situ effect on the transverse shear and transverse compressive strengths of embedded plies [77, 78]. According to these models, not only $Y_{T}^{i s}$ and $S_{L}^{i s}$ are assumed in-situ properties (calculated using e.g. the models proposed by Camanho et al. [69]), but also $Y_{C}^{i s}$ and $S_{T}^{i s}$ (Fig. 9).

In multi-directional laminates, transverse shear cracks typically appear as inclined mode I transverse shear cusps (Fig. 10), which deflect into delaminations [79]. Similarly to constrained transverse plies loaded in tension, the constraining effect of the stiffer adjacent plies reduces the available elastic energy within the ply, delaying transverse shear crack growth in the matrix [4, 70-72]. Although there is no direct experimental evidence of an in-situ effect in transverse shear, analysis models can predict this deterministic size effect [77-79].

Similarly, there is no direct experimental evidence of an in-situ effect in compression. However, recent studies, which addressed directly or indirectly the effect of ply thickness on the compressive properties of multi-directional laminates, indicate that ply thickness affects the compressive response of polymer composites [40, 41, 98]. These observations were later supported by a detailed representation of the mechanics of transverse compressive failure and associated in-situ effect using a 3D computational micro-mechanics framework [81]. A clear in-situ effect in transverse compression was identified (see Figs. 11-12).

Finally, it is noted that analysis models $[77,78,99]$ also predict a positive contribution of the in-situ effect to the resistance to fibre-dominated compressive failure mechanisms (Fig. 13). Assuming that fibre kinking is triggered by localised matrix failure in the vicinity of misaligned fibres, higher matrix in-situ strengths will lead to an enhanced failure behaviour under combined longitudinal compressive and transverse stress states, which can also be related to the improved compressive response of laminates with thin plies [40, 41, 98]. 


\subsection{Delamination}

Delamination between plies is a common damage mechanism in composite laminates due to their relatively weak inter-laminar properties [25, 49]. The structural integrity of composite structures is particularly sensitive to this failure mechanism because, typically, no visual defect is visible from the surface of the laminates, making delamination difficult to detect during visual inspection.

Delaminations can have several sources, including manufacturing defects (due to incomplete curing, introduction of foreign particles, or from transverse cracks caused by residual stresses) [25], impact damage [51, 54, 100-102], early matrix cracking $[26,30,103]$, or geometric discontinuities such as free edges, curved sections, sudden changes of cross section, ply drops, stiffener terminations and flanges, or open holes, which cause high inter-laminar stress concentrations [25, 29, 30, 104].

The study of the effect of ply thickness on delamination onset and growth dates back to the early 1980's [25, 26], when relevant analysis programmes showed that delaminations form at a lower nominal applied strain in laminates scaled by increasing the ply thickness (or the number of plies blocked together). Similar results were reported more recently [27]. Similarly, matrix crackinginduced delamination (MCID) initiates at lower applied strains when the ply thickness increases, findings supported by other authors [85, 105] and by analysis methods [106]. Due to lower in-situ strengths, early ply cracking occurs in the transverse plies (see Fig. 14), causing local stress concentrations at the interfaces with the surrounding plies that induce premature delamination onset. In addition, higher energy release rates (ERRs) at the interfaces between thick plies lead to early delamination onset and growth at those interfaces. The combination of these two effects contribute to the marked reduction of the delamination onset strain shown in Fig. 14 as the number of ply repetitions increases. Fig. 14 also shows that this early delamination onset leads to premature laminate failure, caused by the local stress concentrations at the load carrying plies induced by the early matrix cracks and delaminations. As the transverse plies become thinner, matrix cracking is delayed, forcing delamination to start from the free 
edges. The predominant type of inter-laminar damage changes from MCID to FED (free-edge delamination), delaying laminate failure (see Fig. 14).

More recently, other studies have demonstrated, through direct or indirect experimental observations and analysis methods, the benefits of ply thinness in suppressing the onset and propagation of delamination in coupons $[4,7,16,28-$ 30, 80, 95, 107, 108] and structural details [109]. It is interesting to note that, based on numerical studies, independently of the ultimate failure mode, neglecting delamination in the analysis of conventional laminates leads to inaccurate predictions of the ultimate strengths [39]. However, given the ability of thinply laminates to suppress delamination, complex nonlinear analysis models that simulate inter-laminar damage onset and growth are no longer necessary for accurate prediction of the failure behaviour of this class of composite materials $[110,111]$.

Finally, it should be noted that, due to the low out-of-plane strength of composite laminates, their use in applications with important through-thickness stresses, such as those observed in stiffened panels (in particular when subjected to bending loads), ply drops (e.g. from laminate tapering) or L-shaped structures (typical of box structures, such as wings or wind turbine blades), is generally restricted. In fact, delamination failure caused by through-thickness, out-of-plane reactions is one of the main obstacles to the replacement of current metallic curved sections by composite ones in advanced lightweight construction. The ability of thin plies to delay, or even suppress delamination caused by free edge effects without the need of special resins, interleaving solutions or through-thickness reinforcements makes laminates with thin plies also attractive for this type of applications.

\subsection{Fibre failure modes}

\subsubsection{Intra-laminar longitudinal strengths}

Intra-laminar fibre failure is typically characterised by fibre fracture, fibrematrix debonding and subsequent pull-out in tension, or by shear-driven fibre failure and fibre kinking in compression, often leading to ultimate, catastrophic 
laminate failure. It is therefore important to understand how ply thickness can affect intra-laminar failure involving fibre fracture. This has special significance since the strength and the energy released by fibre-dominated failure modes are much larger than those involving matrix-dominated failure modes, either intra-laminar matrix cracking (Sect. 3.2) or delamination (Sect. 3.3).

In tension, a ply thickness effect on the longitudinal ply strengths is not expected [42, 43]. However, the laminate strength is strongly influenced by the thickness of the transverse and off-axis plies due to early matrix cracking (Sect. 3.2) and delamination (Sect. 3.3), as shown in Fig. 14. In fact, the subcritical damage suppression capability of thin plies allows obtaining strains-tofailure approaching the maximum elongation of the reinforcing fibres $[112,113]$, thus exploiting the full load carrying capacity of the composite system. In compression, an effect of the matrix in-situ strengths is also believed to improve the overall response under combined longitudinal compressive and transverse stress states (see Fig. 13).

\subsubsection{Intra-laminar longitudinal fracture toughness}

The determination of the intra-laminar fracture toughness associated with fibre failure modes is currently extremely important in the assessment of the damage tolerance of composite structures and their behaviour during damage propagation [114-117], as well as in the definition of the softening laws used in recent computational analysis models [118-121] and in establishing the energy equilibrium equations used in closed-form solutions [122] that predict the ultimate strength of composite laminates. Because lay-up, geometry and size can affect the measured ERR, care must be taken when determining the fracture toughness associated with this failure mode.

It is also worth noting that, even though the fracture toughness can be characterised by a single parameter, it may be represented more accurately in the form of an $\mathcal{R}$-curve, relating the change in the critical ERR with crack growth [115-117, 123-125], or in the form of a cohesive law, relating the cohesive stresses inside the fracture process zone with the cohesive crack opening [126, 127]. This 
is because intra-laminar damage propagation involving fibre fracture is characterised by growing resistance before the damage process zone is completely developed, namely due to (i) load redistribution resulting from micro-cracking, splitting and/or delamination, which relieve the stress concentration and delays fracture to higher applied loads [122, 128-131], and (ii) bridging by the intact fibres of the plies that are adjacent to the principal load-carrying plies with broken fibres $[129,130]$.

The studies focused on compressive failure are considerably less comprehensive than those on tension [125], even though the intra-laminar fracture toughness, $\mathcal{R}$-curve, or cohesive law associated with the propagation of a kink band are very important in the analysis of the damage tolerance of FRP structures.

Compact Tension (CT) and Compact Compression (CC). The CT configuration (Fig. 15a) is perhaps the most widely used specimen configuration for intralaminar fracture toughness measurement of composites [125]. For characterisation of the compressive fracture toughness, a configuration similar to the CT test specimen has also been used by reversal of the loading configuration, known as the CC test specimen (Fig. 15b) [123, 125].

CT-type tests are usually devised such that extraneous damage modes are minimised and a brittle type of crack progression occurs from the pre-machined notch to measure the laminate or the ply intra-laminar fracture toughness. However, whereas dispersed-ply laminates exhibit stable crack growth through the whole thickness, blocked-ply laminates are characterised by a large amount of splitting and delamination [33].

In laminates with dispersed plies, the local stress at the notch tip is sufficiently high to allow through-thickness crack progression across the width of the specimen due to the absence of blunting effects as a result of reduced sub-critical damage. The constraining effect imposed by the off-axis plies on dispersed $0^{\circ}$ plies prevents the occurrence of split cracking (in-plane shear matrix cracks, Sect. 3.2.3), resulting in the desired brittle type of failure mode. This split cracking suppression is specially strong in thin-ply laminates (Fig. 16). 
Laminates with blocked plies, however, are characterised by a larger damage process zone due to the development of splitting and delamination (Fig. 17a) [34-36], which can be attributed to the lower constraint [44] and higher ERR at the interfaces adjacent to the $0^{\circ}$ ply blocks. Damage often spreads from the pre-notch without clear through-thickness fracture propagation [132]. This leads to a significant reduction of the stress concentration at the notch tip that ultimately conducts to an apparent tougher laminate. This apparent increase of the intra-laminar fracture toughness for fibre tensile failure modes has been also attributed to an increase in fibre pull-out in the thicker $0^{\circ}$ layers (Fig. 17b) [37].

Based on these results, a ply thickness effect on the energy released during intra-laminar fibre tensile failure has been documented [13, 37, 133], suggesting that the intra-laminar fracture toughness associated with mode I crack propagation perpendicularly to the fibre direction is not simply a material property, but rather an in situ property [37, 114], in spite of contradictory results showing no notable difference in the intra-laminar fracture toughness of quasi-isotropic laminates with dispersed or blocked plies $[33,38]$. In fact, the occurrence or extent of other failure mechanisms and their effect on the measured intra-laminar fibre fracture toughness are often not discussed in sufficient detail [13, 37, 38, 133].

Based on the assumption of an in situ intra-laminar fibre fracture toughness, Chen et al. [39] employed a cohesive zone model accounting for a thicknessdependent mode I intra-laminar fracture toughness perpendicular to the fibre direction in the prediction of the tensile strength of open-hole laminates. A simple linear scaling of the fracture toughness with the thickness of the $0^{\circ}$ ply block was applied. Chen et al. [39] concluded that accounting for this dependency is necessary to predict ply thickness effects in multi-directional laminates. However, the effect of other damage mechanisms such as splitting or delamination was not detailed.

Because split cracking and local delamination in the vicinity of the crack tip blunts the stress concentration, crack restraining in thick $0^{\circ}$ plies cannot be attributed solely to an intrinsically higher fracture resistance, as the apparent 
increase of fracture toughness is due to the development of a large damage process zone containing split cracking and localised delaminations that modifies the stress field in the vicinity of the notch tip, as detailed earlier by Li et al. [33]. Intra-laminar fracture toughness scaling [39] allows accounting for the additional stress relaxation that results from the development of a larger damage process zone. However, it is not clear whether such virtual scaling of the fracture toughness is applicable to more complex loading scenarios, where the sequence and extent of the blunting mechanisms can be different.

By suppressing split cracking (e.g. Fig. 16a), stress redistribution ahead of the crack tip is precluded in laminates with thin plies, leading to a lower apparent fracture toughness. This effect was confirmed by Bullegas et al. [134], by showing that the intra-laminar fibre fracture toughness of thin-ply laminates can be increased several fold when split cracking is favoured through properly placed micro-cut patterns ahead of the crack front, promoting bundle pull-out during crack propagation (Fig. 17b).

Size effect law. As an alternative to CT- and CC-type test specimens, a methodology based on the size effect law [135] can be used to measure the intra-laminar fracture toughness and the $\mathcal{R}$-curve of composite laminates in mode I tension $[116,136]$ and compression [115], as well as in mode II [117]. According to this methodology, the $\mathcal{R}$-curve can be measured taking into account that, for different characteristic sizes $\left(w_{n}\right)$, assuming that the size effect law $\bar{\sigma}^{\infty}=\bar{\sigma}^{\infty}(w)$ is known, the driving force curves $\mathcal{G}_{I}$ at the ultimate remote stresses $\left(\bar{\sigma}^{\infty}\left(w_{n}\right)\right)$ are tangent to the $\mathcal{R}$-curve (Fig. 18). In other words, the $\mathcal{R}$-curve can be determined as the envelope of the crack driving force curves at the ultimate remote stresses (e.g. Ref. [137]). The size effect law can be easily obtained from geometrically 
similar specimens ${ }^{1}$ of different sizes with a positive geometry ${ }^{2}$ [115-117].

Using the size effect method, Catalanotti et al. [116] obtained the $\mathcal{R}$-curve associated with intra-laminar fracture of different carbon/epoxy systems and reinforcements (including non-crimp and woven fabrics). Scaled double edgenotched specimens (Fig. 18) were used. One of the laminates tested by Catalanotti et al. [116] was an NCF thin-ply laminate, with a minimum nominal ply thickness of $0.080 \mathrm{~mm}$. When compared with conventional laminates (nominal ply thickness of $0.125 \mathrm{~mm}$ ), the value of the intra-laminar fracture toughness of the $0^{\circ}$ ply, estimated using the model presented by Camanho and Catalanotti [140], and the length of the fracture process zone indicates that laminates with thin plies are not inherently brittle ${ }^{3}$. Although sub-critical failure mechanisms such as delamination and splitting were apparently absent, a crack resistance behaviour was still observed, which could be linked to a crack bridging phenomenon ahead of the crack tip [122].

Notched strength. Notched specimen configurations are often used in the design process of composite structures to account for the effects of the presence of high stress concentrations, originated, for instance, by discrete sources of damage [141]. The Centre-Notched Tension (CNT) configuration is perhaps the most widely used.

CNT specimens can also be used to measure the mode I tensile fracture toughness of composite laminates [40,41, 125, 140], while a similar configu-

\footnotetext{
${ }^{1}$ Geometrically similar specimens have constant ratio between the characteristic dimension, e.g. the width of the specimen, and the remaining dimensions, namely the crack length and the gauge length of the specimen. Although not mandatory, the use of geometrically similar specimens in the measurement of the $\mathcal{R}$-curve of polymer composites provides simpler and more accurate solutions [138].

${ }^{2}$ In structures with a positive geometry, the ERR at constant load must increase with crack extension [139]. In other words, the geometry correction factor must be an increasing function of the crack length. Nearly all classical notched fracture specimens have a positive geometry [139].

${ }^{3}$ An inherently brittle material would exhibit a negligible fracture process zone and a low fracture toughness, which is not the case of laminates with thin plies.
} 
ration, the Centre-Notched Compression (CNC), can be used to measure the compressive fracture toughness by reversal of the loading direction [40, 41, 125]. However, a centre-notched specimen alone only provides a single value of the intra-laminar fracture toughness, which is below the steady-state value unless a sufficiently large centre-notched specimen, able to develop the full fracture process zone (FPZ), is tested; the characterisation of the $\mathcal{R}$-curve is therefore not possible.

Previous studies $[40,41,122]$ indicate that the ply thickness effect on the intra-laminar fracture of composite laminates is not related with an intrinsically higher fracture toughness of thicker $0^{\circ}$ plies. Instead, it is related with a higher propensity to develop sub-critical damage mechanisms such as delamination due to higher inter-laminar stresses at the interfaces between thicker plies, and longitudinal split cracking due to lower in situ shear strengths that allow the development of matrix cracks parallel to the fibre direction (Fig. 17a). These damage mechanisms cause a stress redistribution around the notch tip that delays intra-laminar fracture perpendicularly to the fibres, leading to an important notch blunting effect [40, 142], and apparently increasing the laminate fracture toughness, as explained earlier.

Discussion. Based on these observations, it seems that the development of subcritical damage mechanisms, specially longitudinal split cracking, is the main reason for the differences in the measured intra-laminar fracture toughness for laminates with different ply thickness. This observation motivated Furtado et al. [42] and Arteiro et al. [43] to combine $0^{\circ}$ ply blocks with dispersed transverse and off-axis thin plies to successfully increase the notched strength of thin-ply laminates without compromising their intrinsically high un-notched strength.

Finally, it is noted that the existence of different techniques to measure the intra-laminar fracture toughness associated with mode I crack propagation perpendicularly to the fibre direction hinders a definitive conclusion about the effect of ply thickness on this property, and, therefore, further studies are still required to improve the knowledge about this topic. 


\subsection{Size effects}

The mechanical response of a composite laminate is usually dependent on the coupon size (or volume), even when all other characteristics are preserved. The understanding of this size effect is of great importance when using strength data from small coupons in the design of large load-bearing structures [35, 138, $139,143,144]$.

\subsubsection{Size effects in smooth coupons}

Detailed studies show that the un-notched strengths of multi-directional composite laminates with sub-laminate scaling, where the basic sub-laminate is repeated as often as required to increase the laminate thickness (and the thickness of each UD layer is therefore constant and equal to the thickness of a single ply) is higher than laminates with ply scaling, where plies of the same orientation are stacked together to increase the effective ply thickness (Fig. 19) [44-47]. These studies also show that laminates scaled at the sub-laminate level exhibit no load drops or visual indications of damage prior to ultimate failure, which is characterised by a fairly clean break across the width in the gauge section. Laminates scaled at the ply level, on the other hand, exhibit transverse and split cracking and delamination from the off-axis plies, leading to a detrimental size effect (Fig. 19).

\subsubsection{Hole size effects in tension}

When a notched multi-directional laminate is loaded in tension, fibre-matrix splitting in the $0^{\circ}$ plies and localised delaminations can occur at the hole edge, acting as important notch blunting mechanisms that affect the stress concentration at the hole edge, and consequently the notched strength. But as the hole size increases, it becomes more difficult for the delaminations to grow and link through-the-thickness, and for splitting to occur, leading to a hole size effect characterised by a change in strength of laminates with a centrally located open hole of different sizes, but constant stress concentration across the width (i.e. 
constant width-to-hole diameter ratio $^{4}$ ) [48-50].

The hole size effect is generally dependent on many factors, and therefore not always result in the same trends for all laminates. In particular, ply thickness plays an important role on these trends, which can be explained by the role of sub-critical damage in the laminate failure mode [49].

Laminates with sufficiently thin plies fail by fibre fracture, because the fibre failure stress is reached before extensive delamination growth and fibre-matrix splitting $[48,49]$. Intra-laminar fracture initiates at the hole edge and propagates across the width, sometimes restricted to the outermost sub-laminate [48, 145]. This leads to a fibre failure mode, with either pull-out or brittle appearance, depending on the extent of matrix damage mechanisms. As the hole size increases, delamination propagation becomes more localised, reducing further the blunting effect of delamination and splitting, and decreasing the notched strength, giving rise to the conventional hole size effect (Fig. 20).

With sufficiently thick plies (or thick ply blocks), delamination becomes the predominant failure mechanism, which easily propagates across the width until reaching the straight free edges of the specimen. Delamination then steps through the adjacent interfaces via transverse and off-axis matrix cracks, reaching the interface with the $0^{\circ}$ plies, and isolating them $[48,145]$. This leads to complete gauge section delamination of the interfaces adjacent to the $0^{\circ}$ plies, resulting in early delamination failure [48, 49]. Even though the specimens may be able to sustain additional loading due to the load carrying capacity of the remaining $0^{\circ}$ ligaments, delamination propagation can be considered an appropriate definition of failure because these specimens loose their structural integrity upon delamination propagation [50]. By increasing the hole size, and keeping constant the width-to-hole diameter ratio, it becomes harder for the delaminations to propagate and join up across the wider ligaments before fibre fracture. In these conditions, complete loss of structural integrity is de-

\footnotetext{
${ }^{4}$ It is important to note that when the width is kept constant for varying hole sizes, the varying stress distribution across the width may obscure the underlying size effects [50].
} 
layed and the notched strength increases, resulting in an inverse hole size effect [48, 49, 145] (Fig. 20).

For laminates with intermediate ply thickness, a transition of failure mechanisms, from delamination to fibre failure, may occur as the coupon size increases. Specimens with small holes may fail by delamination, and specimens with large holes may fail by fibre fracture. In these cases, the competing failure mechanisms can lead to a flat response, with an almost constant notched strength over a range of hole sizes [48, 49].

Based on these observations, Wisnom and co-workers [48, 49] concluded that the hole diameter-to-ply block thickness ratio is the critical parameter affecting how easily delaminations propagate, and consequently how the laminate strengths change with changing hole diameters. For high hole diameter-to-ply block thickness ratios - the case of laminates with thin plies — delamination is not likely to occur. These observations have been confirmed not only on conventional laminates [40], but also on NCF thin-ply laminates [15, 41].

\subsubsection{Hole size effects in compression}

For the hole size effect in compression, three distinct failure mechanisms, all possibly leading to catastrophic failure, have been observed depending on size and lay-up, namely longitudinal compressive failure induced by shear-driven fibre fracture or by fibre kinking, push-out between plies and delamination [50]. Laminates with sufficiently thin plies exhibit a more brittle failure mode, characterised by a straight fracture across the laminate. Since sub-critical damage mechanisms, such as delamination and fibre splitting, are inhibited by the constraining effect of the thinner sub-laminates, the stress in the $0^{\circ}$ plies increases to a level high enough to trigger longitudinal compressive failure. Laminates with thick plies (or thick ply blocks) show fracture of the angle plies, fibrematrix splitting and local delamination or push-out between plies before $0^{\circ}$ ply failure (Fig. 21). This local damage leads to a stress redistribution around the hole, reducing the stress concentration and delaying ultimate laminate failure to a higher applied stress. For this reason, the compressive notched strengths 
of laminates with blocked plies tend to be higher than the notched strengths of laminates with thin plies [15, 40, 41, 46, 47].

It is noted, however, that results presented elsewhere $[4,6,14,146]$ show that laminates with thinner plies have equal or higher compressive notched strengths. On one hand, the type and extent of the damage that develops around the hole can be affected by the boundary conditions used to support and load the specimen in compression (e.g. out-of-plane constraining), contributing to the observed differences. On the other hand, the intrinsically higher compressive strength of spread-tow UD plies [4] and fabrics [6] promoted by their superior micro- and meso-structural uniformity (Sect. 2.1) also contributes to an improved compressive notched response; despite the lack of stress relaxation due to the absence of sub-critical damage mechanisms, the higher compressive strengths of the $0^{\circ}$ thin plies delay laminate failure, even in the presence of a notch. It is therefore clear that, to account for the effect of ply thickness on the compressive strength of notched laminates, it is not only important to understand meso-scale effects such as the type and extent of damage prior to ultimate failure, but also the role of extrinsic and intrinsic factors such boundary conditions and micro-structural characteristics.

\subsubsection{Effect of laminate thickness}

Wisnom et al. [50], after gathering extensive work on scaling of un-notched and open-hole specimens, discussed the effect of laminate thickness on the strength of laminates, and how ply thickness scaling affects the observed trends. Increasing the laminate thickness by ply scaling leads to a severe tensile strength reduction in the un-notched and open-hole laminates, which show very similar trends (Figs. 19 and 22). This is attributed to easier delamination propagation as the laminate thickness increases with ply thickness.

Thickness scaling of un-notched laminates using sub-laminate repetitions leads to a slight strength increase (Fig. 19). Matrix cracking starts in the outer plies [69], which represent a smaller portion of the thicker laminates with dispersed plies, leading to higher laminate un-notched strengths as the laminate 
thickness increases. However, notched laminates with dispersed plies show a slight reduction in tensile strength with increasing laminate thickness, remaining constant for increasingly thicker laminates (Fig. 22). In this case, as opposed to the un-notched laminates, damage development in the outer plies (which represent a smaller portion of the thicker laminates) leads to a reduced notch blunting effect around the hole, increasing the stress concentration, leading to premature laminate failure.

In compression, un-notched laminates with sub-laminate scaling do not show significant thickness scaling effects, with a fairly constant compressive strength regardless of the specimen thickness (Fig. 19) [50, 146]. Un-notched laminates with ply scaling, on the other hand, exhibit a strength reduction with increasing laminate thickness (Fig. 19). Fibre waviness and void content [146] and a change in failure mode to delamination [50] are reportedly the main contributors to the thickness effect on the compressive failure strength of laminates with ply scaling.

Conversely, the compressive notched strength of dispersed-ply and blockedply laminates is fairly insensitive to laminate thickness (Fig. 23), despite a change of failure mode to delamination (with no fibre breakage) in thicker laminates [50].

\subsubsection{Discussion}

Currently, it is well understood that structures subjected to uniform, smooth stress distributions in uniaxial tension or uniaxial compression can benefit from constructions based on laminates with thin, dispersed plies. However, in the presence of stress concentrations, the lack of notch blunting mechanisms may lead to higher notch sensitivity, specially in tension (Sect. 3.5.2).

To ensure a damage tolerant design with thin plies, sub-critical damage should be allowed to grow near the stress concentrations, preferably without compromising the un-notched strengths of the laminate. This has been achieved by combining thin transverse and off-axis plies with thick (or intermediate) $0^{\circ}$ plies to promote longitudinal split cracking tangent to the notch boundary, relieving the stress concentration, and thus promoting the desired notch blunting 
effect [42, 43]; more interestingly, the presence of thick (or intermediate) $0^{\circ}$ plies do not compromise the intrinsically high un-notched strengths of thin-ply laminates $[42,43]$.

In compression, the effect of sub-critical damage preceding ultimate failure on the laminate compressive notched strength may depend substantially on the local boundary and loading conditions; nevertheless, more recent results on spread-tow thin-ply laminates suggest that the ply uniformity and damage suppression capability of thin plies lead to a superior compressive notched strength by delaying fibre compressive failure to higher loads in spite of the local stress concentration promoted by the absence of notch blunting mechanisms $[4,6,14]$.

Finally, it is important to stress that in laminates with thin plies, since delamination and matrix cracking are precluded, failure analysis becomes simpler since closed-form solutions or simple modelling strategies can be used to predict with reasonable accuracy the notched strengths and notch size effects on such laminates $[15,79,110,111,122]$. Conversely, in laminates with standard or thick plies, delamination and split cracking are likely to occur. Consequently, their mechanical response can only be predicted using nonlinear finite element (FE) codes [39, 147], which are usually unsuitable for preliminary design or optimisation. This is a relevant advantage of thin plies, specially in applications that require complex material scrutiny and certification procedures, for fast and optimal laminate selection, or when the time and resources to run advanced FE codes are limited.

\subsection{Impact resistance and damage tolerance}

Load bearing structures made of composite laminates, particularly those used in aerospace applications, must have their design driven by damage tolerance considerations, i.e. some level of damage must be assumed to exist in the composite structure $[101,148]$. The reason for this is the susceptibility of composite laminates to the introduction of visually undetectable damage caused by external sources such as out-of-plane low-velocity impact (LVI) events by foreign objects. 
LVI events usually lead to the formation of local delaminations below and around the impact location that are particularly critical for the compressive strength of the impacted composite laminate [149]. Impact damage has, therefore, a significant effect on the residual compressive and shear strengths of composite laminates due to the appearance of instabilities and overloading of the undamaged areas, reducing the load-carrying capacity and structural integrity of composite structures $[51,53,54,100,101,149,150]$.

In laminates with thick plies (or thick ply blocks), the number of interfaces available for delamination is reduced, leading to fewer, but larger delaminations when subjected to impact loading [51-56], and consequently lower delamination threshold loads and lower peak forces (Fig. 24). This is typically prejudicial for the impact response of the laminate [55].

However, when assessing the effect of ply thickness on the residual compressive strength measured in compression after impact (CAI) tests, the trends are not so clear $[52-55,100]$. On one hand, the residual compressive strength of laminated composites with thick plies (or thick ply blocks) is expected to decrease due to larger delaminations, which reduce the laminate bending stiffness and, therefore, increase the susceptibility to local buckling. On the other hand, if the number of delamination planes increases, which is expected to happen when the number of plies in a laminate is higher $[54,55]$, as in laminates with thin plies, the residual compressive strength is also expected to decrease due to the formation of thinner sub-laminates that are more susceptible to local buckling. The lack of a clear trend for the effect of ply thickness on the residual compressive strength of conventional laminates is confirmed by the number of experimental studies with contradictory conclusions [51-54].

In the case of very thin plies, the overall size of delamination damage is reportedly similar to that of blocked-ply laminates [14, 28], confirmed by quasistatic indentation studies [31, 32]. However, these results contradict the typical observations on laminates with conventional dispersed and blocked plies [5156]. Although matrix cracking and delamination onset are delayed in laminates with thin plies [57], earlier fibre breakage on the impacted and non-impacted 
faces $[4,31,58,59]$ (due to very high compressive and tensile stresses) and large delaminations at the mid-surface $[4,32,57,59,60,151,152]$ (where the highest shear stresses occur) appear in these laminates, an observation that was also confirmed numerically [153]. Deeper indentation footprints can also be expected due to the high local compressive stresses beneath the impactor, which can reduce the threshold for barely visible impact damage and lead to higher residual strengths at the threshold of detectability.

In spite of this characteristic impact damage morphology, some authors reported a superior CAI response in laminates with thin plies [28, 57]. Although large projected delamination areas [59], typically due to the propagation of a single or few large delaminations [57, 60], are observed, the resulting sub-laminates are substantially thicker than those originated in thick-ply laminates, leading to an improved CAI response. This superior CAI strength is also attributed to an intrinsically higher compressive strength due to an improved micro-structural uniformity (Sect. 2.1), and to a fine dispersion between plies of different fibre orientation that restrains fibre kinking [57].

However, more recent studies report decreasing damage tolerance with ply thinness in compression [59, 152], as well as in tension [151], attributed to extensive fibre failure during the impact stage [59]; this is specially critical in thin laminates [58-60]. Moreover, since fibre breakage is one of the predominant damage mechanisms in thin laminates with thin plies, its extent also dictates the reduction of residual compressive strength with increasing impact energy [154], not just the projected damage area as in conventional laminates.

Based on the previous observations, it is recognised that the effect of ply thickness scaling on the impact resistance and damage tolerance of composite laminates is more complex than the effect of ply thickness scaling on the intraand inter-laminar failure modes alone. While an improved impact resistance is usually reported for laminates with dispersed plies of intermediate thickness $[4,51-54,59]$, laminates with thin plies exhibit early fibre breakage due to the delay of delamination and matrix cracking, compromising their impact response.

These observations also suggest that, from a damage resistance and damage 
tolerance point of view, laminates with thin plies have to be addressed differently from conventional composites [79]. The characteristic mechanical behaviour under impact of laminates with thin plies must be taken into account in the design process to fully exploit their special features. Since fibre fracture and deeper indentation footprints appear earlier in the laminate $[59,60]$, which then cause the delaminations inside, undetectable damage due to impact may not be of concern; in other words, once damage occurs, it may be immediately detectable. Therefore, instead of designing thin-ply composite structures for damage tolerance, it may be necessary to design them specifically for impact (fibre fracture) resistance.

Alternatively, thin plies can be combined with other material technologies for an optimum structural response. This has been achieved through combination of thin plies with more advanced, tougher matrix formulations and interface interleaving $[113,155,156]$. Such toughened thin-ply composites can have damage tolerances within the standard requirements of damage-tolerant design, without compromising the composite strengths. This is possible due to strong delamination suppression; interleaving thermoplastic veils can arrest delamination onset and consequently improve the residual strength of laminates with thin plies $[113,155,156]$.

Improvements of the damage tolerance of laminates with thin plies can also be achieved through hybrid solutions [58] combining thick or standard plies with thin plies [42, 43], and through proper, more flexible laminate design [60]. On one hand, ply thickness hybridisation can alleviate the amount of fibre failure with increased delamination damage, improving damage tolerance [58]. In addition, the introduction of $0^{\circ}$-ply blocking, namely at the outer layers of the laminate, can improve the post-impact response, attributed to an increase of the bending stiffness of the surface sub-laminates [55]. On the other hand, motivated by the unsymmetrical nature of the damage modes induced by LVI in the laminate thickness direction, unsymmetrical designs have been proposed [60], enlarging the design space for optimal hybrid solutions combining thick or standard plies with thin plies. Appropriate unsymmetrical designs allow con- 
trolling the position of the dominant delaminations caused by LVI, moving them away of the interfaces close to the mid-surface (as typically observed in laminates with thin plies $[57,60,151])$, while reducing the projected damage area and the extent of fibre breakage. This leads to the formation of a thick intact sub-laminate, improving damage tolerance.

\subsection{Fatigue}

Due to the ability of high performance reinforcements such as carbon fibres to transmit and disperse the high-frequency vibration loads, polymer matrix composite materials with continuous fibres are very effective when subjected to mechanical fatigue [61]. Nevertheless, cyclic loading is still a very important precursor of sub-critical damage mechanisms in composite laminates that result in the degradation of composite structures.

When subjected to cyclic loading, standard composite laminates experience damage initiation by transverse cracking in the matrix, which occurs in the very early stages of the fatigue life of the material. While not affecting the structural response and the resistance to longitudinal damage propagation, these transverse cracks induce local delaminations, which propagate under fatigue loading $[61,157,158]$, causing stress redistributions that affect the residual stiffness, the residual strength and the fatigue life of the laminate $[26,49,61$, $157]$.

In the case of notched coupons under fatigue loading, the development of sub-critical damage is enhanced, since the relative damage growth rates will not be the same and matrix-dominated failure modes such as matrix cracking and delamination are likely to become more dominant before fibre failure (Fig. 25). In addition, damage development is more progressive and more dispersed in the $90^{\circ}$ plies than in quasi-static loading [61].

Since decreasing ply thickness leads to the suppression of matrix-dominated damage mechanisms such as matrix cracking and delamination, which are the cause of material degradation under cyclic loading, laminates with thin plies expectedly show enhanced fatigue life behaviour. The constraining effect on 
thinner transverse plies leads to limited growth of micro-cracking $[4,5,14,27$, 28, 62, 112] and delamination [4, 28, 112] (Fig. 26), regardless of the stress level $[27,112]$ and sign of the stress ratio [112], up to a point where no stiffness degradation nor damage accumulation is observed [4]. Consequently, the fatigue lifetime of spread-tow woven $[5,62]$ and tape laminates $[4,14]$ is markedly superior to that of conventional laminates.

It is worth noting that the certification of primary composite structures, for example in aerospace applications, is typically based on "no growth" criteria for delaminations emanating from stress raisers such as ply drops or free edges [158]. Therefore, the intrinsic damage suppression capability and improved fatigue life of laminates with thin plies may result in benefits when it comes to the certification of airborne composite structures based on this kind of criteria.

\subsection{Bearing strength}

Virtually every large-scale composite structure contains joints. The reasons behind their use include manufacturing constraints and requirements related to accessibility to the structure, quality control, structural integrity assessment, and part replacement. Among the types of joints used in large-scale composite structures, mechanically fastened joints are particularly common, and often the only feasible solution. However, due to the stress concentrations created, mechanically fastened joints are generally the critical part of a composite structure, as they are a source of weakness and compliance [159-163]; consequently, the soundness of the joint design procedure used is reflected on the overall weight and cost of the composite structure.

The behaviour of composites in bolted joints differs considerably from that of metals. The quasi-brittle nature of composite materials requires more detailed analysis to address the different damage mechanisms occurring in the vicinity of the loaded fasteners. Therefore, when designing composite joints, several factors need to be taken into account, including the orthotropy of the laminates (which may promote higher stress concentrations) and geometrical parameters such as edge distances and hole spacings [141, 162]. These lead to different fail- 
ure modes, namely bearing, net-tension, shear-out, cleavage and tear-out when subjected to in-plane loading (Fig. 27) [164], or pull-through when subjected to out-of-plane loading [165].

Bearing failure is one of the most common failure modes, which occurs predominantly when the fastener diameter is a small fraction of the plate width. This is a progressive, non-catastrophic failure mode and occurs when the laminate is no longer capable of sustaining the accumulated local damage $[160,166]$. Before ultimate failure, damage starts as localised delaminations, followed by matrix cracks through the thickness of the plies, which lead to further delaminations [167]. Bearing failure is also related to fibre kinking and fibre-matrix crushing [168]. This progressive failure mode typically leads to a permanent deformation of the hole [160] that can affect the integrity and functionality of the structure.

Given the ability of laminates with thin plies to delay, or even suppress, sub-critical, progressive damage mechanisms such as delamination and matrix cracking, an improved performance of these materials when subjected to bearing loads is expected. Thinner plies lead to lower intra-laminar shear stresses [169], delaying the onset and propagation of damage mechanisms such as matrix cracking, fibre kinking and through-thickness shear cracking [4, 41], and lead to higher delamination onset loads and, consequently, smaller initial delaminated areas $[4,170]$. The result is a superior bearing performance of laminates with thinner plies [41] at room and hot-wet conditions [4].

\subsection{Environmental exposure}

In a multi-directional laminate, the different ply orientations lead to a mismatch of the coefficients of thermal and moisture expansion. Moreover, temperature and moisture are known to aggressively affect the polymer matrix, degrading the mechanical properties of composite laminates [4]. Hence, the temperature variation during the curing process and the in-service environment can lead to early matrix cracking and inter-laminar damage growth. However, with thin plies, matrix cracking constraining (Sect. 3.2) and lower inter-laminar 
stresses (Sect. 3.3) can be expected, also under thermal- and moisture-induced loadings. Therefore, the sensitivity of laminates with thinner plies to temperature and environmental effects is likely to be lower.

This feature of thin-ply laminates can be exploited to improve the resistance also under extreme environmental conditions, such as applications on low earth orbit (LEO) environments [63] and hot-wet conditions [4]. For example, thin-ply laminates show improved tensile strength either with or without LEO environment exposure, exhibiting a stable mechanical response independently of the environmental conditions [63].

\subsection{Lightning strike resistance and other multifunctional properties}

Low-conductive FRPs are more vulnerable to lightning-induced damage than metals. During a lightning strike to a composite structure, several direct effects can be distinguished, such as thermal effects caused by the electric arc, thermal and electrodynamic effects induced by circulation of the lightning current, and mechanical effects from air and surface shock waves. To prevent hazardous events such as catastrophic structural damage, composite structures need to be designed against these lightning direct effects [171].

When subjected to simulated lightning strikes, thin plies reportedly contribute to the reduction of lightning-induced damage, specially bulk damage, including delamination (Fig. 28) [64]. This lightning damage suppression capability results from the lower in-plane and out-of-plane electrical resistivity of laminates with thin plies $[64,172]$. The applied lightning current seems to flow not only in the first, top ply, but also in the underlying plies when these are sufficiently thin, restricting more efficiently the resin vaporisation area due to lower electrical anisotropy as compared with laminates with thicker UD tapes [64]. Moreover, after being subjected to a lightning strike, laminates with thinner plies exhibit higher residual strength [65]. This favours the application of these laminates on advanced, safety-critical composite structures that may be subjected to lightning strikes [64]. 
The adoption of thin plies in laminate design also allows further improvements of the electrical conductivity with recourse to other material technologies, such as carbon nano-tubes directly grown on the carbon fibres, motivated by the more uniform fibre distribution and ply thinness [173]. These characteristics can bring improvements to physical properties such as electrical and thermal conductivity and facilitate the introduction of multi-functionality into FRPs without compromising their intrinsically high specific elastic and strength properties [173].

\section{Opportunities in manufacturing and design}

\subsection{Ply uniformity}

At first, it might appear that part production using laminates with thin plies will result in a clear disadvantage: per laminate thickness, more plies will have to be accommodated, which may result in an increased processing effort that increases with the number of plies (or ply thinness) to reach a target laminate thickness. Therefore, the effective use of thin plies in laminate design must rely on a substantially different approach, using novel reinforcement architectures enabled by the unique uniformity of thin plies. For example, thin plies reduce the degree of waviness caused by the insertion of the weft threads in non-crimp fabrics or the crimp angle and tow flexure in woven fabrics, improving the mechanical properties of this kind of reinforcements $[6,41,174]$, which become sound alternatives to UD tapes. In spite of the additional spreading step prior to the stabilisation and laying or weaving steps, which contributes to an increase of the relative cost of spread tows, heavier tow yarns — with up to $100 \mathrm{k}$ or 200k fibre counts - can be used to reduce the cost of the source fibre tows, as opposed to the very expensive $6 \mathrm{k}$ or $1 \mathrm{k}$ yarns of conventional tows required to obtain sufficiently thin tapes and woven fabrics.

In addition, this unique uniformity leads to excellent surface appearance that may help reducing part production costs in terms of surface finishing and painting (Fig. 29). The improved fibre distribution also favours wider inter- 
fibre spacing, which allows easier flow of the matrix material, either in liquid moulding techniques employing thermosetting resins, or during impregnation by thermoplastic matrices [174], leading to fewer weak zones, i.e., thin plies lead to lower void content and smaller resin-rich areas [89, 174]. However, this wider inter-fibre spacing leads to lower fibre volume fractions in spread-tow yarns [62]. In addition, the number of resin-rich interfaces between layers is higher in thinply laminates (since they have more layers for the same thickness), increasing the relative amount of resin in the laminate. Consequently, the fibre volume fraction of thin-ply laminates is usually lower than the fibre volume fraction of conventional composite laminates [4]. However, this difference is typically small, with no implications reported so far [4].

Interestingly, the overall fibre volume fraction of spread-tow and conventional woven laminates is identical, in spite of the lower fibre volume fraction of spreadtow yarns [62]. This is attributed to the resin-rich areas between the tows in conventional fabrics that reduce the overall fibre volume fraction of the laminate [62]. In spread-tow fabric laminates, the amount of resin between the tows is very small, and, therefore, the fibre volume fraction of the fabric is similar to the fibre volume fraction in the yarns [62]; conversely, in conventional fabrics, due to the amount of resin between the tows, the fibre volume fraction is typically lower than the fibre volume fraction of the corresponding yarns.

Ply thickness has also a noticeable effect on the occurrence of damage during manufacturing. In spite of the mismatch of coefficients of thermal expansion between plies with different fibre orientation, thinner plies suppress thermallyinduced damage [105, 175] as a result of the in-situ effect previously discussed. For example, Fernberg and Joffe [94], through free-edge inspection, observed very few to no transverse cracks in spread-tow fabric laminates after manufacturing, as opposed to conventional woven fabrics.

Another advantage of ply thinness is the design of ply drops, which become much smoother (Fig. 30). Not only the appearance is improved, but also the structural performance of the laminates due to lower ERR at the interfaces between ply drops. 


\subsection{Laminate design, homogenisation and hybridisation}

With thinner plies, for the same laminate thickness, more plies can be accommodated. On one hand, the design space widens, due to higher flexibility in accommodating plies of different orientation. On the other hand, laminate homogenisation by sub-laminate repetition is easier to achieve for the typical laminate thickness currently used in advanced structural design. In this case, mid-plane symmetry becomes irrelevant ${ }^{5}$ due to negligible thermal warpage $[176,177]$. This can be beneficial, for example, in the design of stringers for aero-structures, where criteria to avoid warpage are required. With homogenised laminates, optimisation may rely only on topological optimisation, since warpage is negligible. This also enables simpler lay-up processes, since reversing the stacking sequence at the mid-plane is no longer needed. Continuous stacking becomes possible, and ply drops no longer need to be symmetric, reducing processing time, cost, waste and stacking errors. Besides, by avoiding the symmetry rule, the laminate design space widens further and optimisation for out-of-plane loading and damage tolerance, where non-symmetric laminates may perform better [60], becomes easier [178].

By allowing a higher number of repeated sub-laminates, the potential for overall laminate thickness reduction on buckling- and damage tolerance-driven laminate design also increases [179]. In addition, minimum gauge structures are expected to benefit from the introduction of thin plies due to lower discrete steps in ply thickness; when the theoretical minimum gauge corresponds to a non-integer number of plies, adding one thin ply will lead to thinner, and therefore lighter structures than adding one conventional ply.

Having more plies per laminate thickness also leads to the possibility of using smaller relative ply orientations between adjacent plies, which further improves delamination [180] and impact resistance [181]. It is also noted that

\footnotetext{
${ }^{5} \mathrm{~A}$ laminate is homogenised when the normalised flexural stiffness matrix $\left[D^{*}\right]$ approaches that of the in-plane stiffness matrix $\left[A^{*}\right]$, and the bending-extension coupling terms $\left[B^{*}\right]$ tend to zero.
} 
sub-laminates with smaller relative ply orientations reduce the gap between FPF and LPF (last-ply failure) in such a way that matrix cracking can be completely suppressed before ultimate failure. Together with lower ERRs at the interfaces between plies due to ply thinness, shallow-angle thin-ply sub-laminates allow, for example, the exploitation of the nonlinear deformation of angle-ply laminates to generate more progressive and ductile failure modes in advanced composites $[82,182]$.

Thin carbon plies also allow the production, through hybridisation, of composite systems exhibiting progressive fragmentation or multiple cracking instead of sudden, catastrophic ultimate failure [183-189]. With these approaches, higher energy dissipation can be successfully obtained [184, 186-189], but usually at the compromise of ultimate plain and notched strengths [184, 186-188]. It is also worth noting the increase in fibre tensile strain-to-failure due to the hybrid effect in very thin plies [190], showing that the resistance of the carbonfibre reinforced polymer system can be fully exploited within hybrid composites with thin plies.

\subsection{Analysis}

Homogenisation and the absence of sub-critical damage mechanisms such as matrix cracking (Sect. 3.2) and delamination (Sect. 3.3) before final failure makes analysis much faster and simpler. The simplest methods are based on FPF analysis, designing against the occurrence of transverse cracking. But for most conventional laminates, the FPF strain is much lower than the ultimate failure strain of the laminate, and the high specific strength of composites is therefore compromised [191]. In laminates with thin plies, the gap between FPF and LPF is reduced, and the high performance usually associated to composite laminates can be fully utilised by employing closed-form and fast solutions [15, 99, 110, 111]. This brings clear advantages to the design process, specially when involving optimisation and the generation of A- or B-basis allowables by simulation [192].

The suitability of simpler analysis models combined with the intrinsic supe- 
rior strength and increased design space of laminates with thin plies can lead to better optimised laminates and higher consistency in defining safety factors, with great potential for weight savings and, consequently, cost reduction during the conceptual and detailed design stages and during operation.

\section{Concluding remarks}

Ply thickness can have a drastic effect on the structural performance of composite laminates. Based on experimental and numerical observations on composites with thick, intermediate, and thin plies, this review has demonstrated that the latter bring substantial improvements to the plain strengths and design flexibility of composite laminates. In addition, the use of thin plies in primary structural applications, namely those driven by residual strength and damage tolerance requirements, can enhance their mechanical and weight performance. To achieve this, thin plies can be combined with existing material technologies, for instance through ply-level hybridisation, to design laminates with lower notch sensitivity and higher damage tolerance without compromising the intrinsically high un-notched strengths $[42,43,58]$. Alternatively, novel design principles, including lower relative fibre angles and laminate asymmetry, become feasible, providing enhanced structural and damage tolerant responses [60]. Moreover, it is shown that thin plies provide increased opportunities for multifunctional optimisation due to higher design flexibility [173], and for adoption of more efficient manufacturing technologies thanks to improved multi-axial fabrics that do not compromise structural behaviour. Finally, the suitability of simpler analysis models combined with the intrinsic superior strength and increased design space of laminates with thin plies can lead to weight savings and, consequently, cost reduction during conceptual and detailed design and operation thanks to better optimised laminates and higher consistency in defining safety factors. It is concluded that thin-ply composite materials provide new perspectives for innovative structural applications. 


\section{Acknowledgements}

This work was partially funded by AIRBUS under project 2genComp second generation Composites. The authors gratefully acknowledge the support provided by AIRBUS.

The first and last authors would like to thank the financial support provided by the Portuguese Government's FCT - Fundação para a Ciência e a Tecnologia through National Funds in the scope of project MITP-TB/PFM/0005/2013. The second author is also grateful for the support of FCT under the Grant SFRH/BD/115859/2016.

The last author gratefully acknowledges the funding of Project NORTE-010145-FEDER-000022 - SciTech - Science and Technology for Competitive and Sustainable Industries, co-financed by Programa Operacional Regional do Norte (NORTE2020), Fundo Europeu de Desenvolvimento Regional (FEDER).

The authors are also grateful to Prof. S.W. Tsai (Department of Aeronautics and Astronautics, Stanford University, CA USA) for the inspiring discussions and fruitful collaboration.

\section{References}

[1] Kawabe K, Matsuo T, Maekawa Z. New technology for opening various reinforcing fiber tows. J Soc Mat Sci Jpn 1998;47(7):727-34. In Japanese.

[2] Kawabe K. New spreading technology for carbon fiber tow and its application to composite materials. Sen-i Gakkaishi 2008;64(8):262-7. In Japanese.

[3] Quintana Casanovas J, Costa J, Mayugo JA, Galan Llongueras A. Fabrication of hybrid thin ply tapes. IOP Conf Ser: Mater Sci Eng 2018;406:012067.

[4] Amacher R, Cugnoni J, Botsis J, Sorensen L, Smith W, Dransfeld C. Thin ply composites: Experimental characterization and modeling of sizeeffects. Compos Sci Technol 2014;101:121-32. 
[5] Nishikawa Y, Miki T, Okubo K, Fujii T, Kawabe K. Fatigue behaviour of plain-woven $\mathrm{CF}$ /epoxy composites using spread tows (effect of tow thickness on crack formation). Trans Jpn Soc Mech Eng A 2005;71(710):135661. In Japanese.

[6] Arteiro A, Catalanotti G, Xavier J, Linde P, Camanho PP. Effect of tow thickness on the structural response of aerospace-grade spread-tow fabrics. Compos Struct 2017;179:208-23.

[7] Huang C, He M, He Y, Xiao J, Zhang J, Ju S, et al. Exploration relation between interlaminar shear properties of thin-ply laminates under shortbeam bending and meso-structures. J Compos Mater 2018;52(17):237586.

[8] Suo Z, Bao G, Fan B. Delamination $R$-curve phenomena due to damage. J Mech Phys Solids 1992;40(1):1-16.

[9] Albertsen H, Ivens J, Peters P, Wevers M, Verpoest I. Interlaminar fracture toughness of CFRP influenced by fibre surface treatment: Part 1. Experimental results. Compos Sci Technol 1995;54:133-45.

[10] Sørensen BF, Jacobsen TK. Large-scale bridging in composites: R-curves and bridging laws. Compos Part A-Appl S 1998;29A:1443-51.

[11] Airoldi A, Dávila CG. Identification of material parameters for modelling delamination in the presence of fibre bridging. Compos Struct 2012;94:3240-9.

[12] Frossard G, Cugnoni J, Gmür T, Botsis J. Mode I interlaminar fracture of carbon epoxy laminates: Effects of ply thickness. Compos Part A-Appl S 2016;91:1-8.

[13] Frossard G. Fracture of thin-ply composites: effects of ply thickness. Ph.D. thesis; École Polytechnique fédérale de Lausanne; Lausanne; 2017. 
[14] Yokozeki T, Aoki Y, Ogasawara T. Experimental characterization of strength and damage resistance properties of thin-ply carbon fiber/toughened epoxy laminates. Compos Struct 2008;82:382-9.

[15] Arteiro A, Catalanotti G, Xavier J, Camanho PP. Notched response of non-crimp fabric thin-ply laminates: Analysis methods. Compos Sci Technol 2013;88:165-71.

[16] Kalfon-Cohen E, Kopp R, Furtado C, Ni X, Arteiro A, Borstnar G, et al. Synergetic effects of thin plies and aligned carbon nanotube interlaminar reinforcement in composite laminates. Compos Sci Technol 2018;166:1608.

[17] de Morais AB, de Moura MF, Marques AT, de Castro PT. Mode-I interlaminar fracture of carbon/epoxy cross-ply composites. Compos Sci Technol 2002;62:679-86.

[18] Varandas L, Arteiro A, Catalanotti G, Falzon BG. Micromechanical analysis of interlaminar crack propagation between angled plies in mode I tests. Compos Struct 2019;220:827-41.

[19] Garrett KW, Bailey JE. Multiple transverse fracture in $90^{\circ}$ cross-ply laminates of a glass fibre-reinforced polyester. J Mater Sci 1977;12:15768.

[20] Parvizi A, Garrett KW, Bailey JE. Constrained cracking in glass fibrereinforced epoxy cross-ply laminates. J Mater Sci 1978;13:195-201.

[21] Parvizi A, Bailey JE. On multiple transverse cracking in glass fibre epoxy cross-ply laminates. J Mater Sci 1978;13:2131-6.

[22] Flaggs DL, Kural MH. Experimental determination of the in situ transverse lamina strength in graphite/epoxy laminates. J Compos Mater 1982;16:103-16. 
[23] Dvorak GJ, Laws N. Analysis of progressive matrix cracking in composite laminates II. First ply failure. J Compos Mater 1987;21:309-29.

[24] Boniface L, Smith PA, Bader MG. Transverse ply cracking in cross-ply CFRP laminates - Initiation or propagation controlled? J Compos Mater 1997;31(11):1080-112.

[25] O'Brien TK. Characterization of delamination onset and growth in a composite laminate. NASA Technical Memorandum, NASA-TM-81940; NASA Langley Research Center; Hampton, Virginia; 1981.

[26] O'Brien TK. Analysis of local delaminations and their influence on composite laminate behavior. NASA Technical Memorandum 85728/USAAVSCOM Technical Report 83-B-6, NASA-TM-85728; NASA Langley Research Center/U.S. Army AVSCOM; Hampton, Virginia; 1984.

[27] Berthelot JM. Transverse cracking and delamination in cross-ply glassfiber and carbon-fiber reinforced plastic laminates: Static and fatigue loading. Appl Mech Rev 2003;56(1):111-47.

[28] Sihn S, Kim RY, Kawabe K, Tsai SW. Experimental studies of thin-ply laminated composites. Compos Sci Technol 2007;67:996-1008.

[29] Camanho PP, Arteiro A, Turon A, Costa J, Guillamet G. Structural integrity of thin-ply laminates. JEC Compos Mag 2012;71:49-50.

[30] Guillamet G, Turon A, Costa J, Renart J, Linde P, Mayugo JA. Damage occurrence at edges of non-crimp-fabric thin-ply laminates under off-axis uniaxial loading. Compos Sci Technol 2014;98:44-50.

[31] Yokozeki T, Kuroda A, Yoshimura A, Ogasawara T, Aoki T. Damage characterization in thin-ply composite laminates under out-of-plane transverse loading. Compos Struct 2010;93:49-57.

[32] Wagih A, Maimí P, González EV, Blanco N, Sainz de Aja JR, de la Escalera FM, et al. Damage sequence in thin-ply composite laminates under out-of-plane loading. Compos Part A-Appl S 2016;87:66-77. 
[33] Li X, Hallett SR, Wisnom MR, Zobeiry N, Vaziri R, Poursartip A. Experimental study of damage propagation in Over-height Compact Tension tests. Compos Part A-Appl S 2009;40:1891-9.

[34] O'Higgins RM, McCarthy MA, McCarthy CT. Comparison of open hole tension characteristics of high strength glass and carbon fibre-reinforced composite materials. Compos Sci Technol 2008;68:2770-8.

[35] Xu X, Wisnom MR, Mahadik Y, Hallett SR. An experimental investigation into size effects in quasi-isotropic carbon/epoxy laminates with sharp and blunt notches. Compos Sci Technol 2014;100:220-7.

[36] Xu X, Wisnom MR, Mahadik Y, Hallett SR. Scaling of fracture response in Over-height Compact Tension tests. Compos Part A-Appl S 2015;69:40-8.

[37] Laffan MJ, Pinho ST, Robinson P, Iannucci L. Measurement of the in situ ply fracture toughness associated with mode I fibre tensile failure in FRP. Part II: Size and lay-up effects. Compos Sci Technol 2010;70:614-21.

[38] Teixeira RF, Pinho ST, Robinson P. Translaminar fracture toughness of CFRP: from the toughness of individual plies to the toughness of the laminates. In: Proceedings of ECCM15. Venice; 2012, p. 1-8.

[39] Chen BY, Tay TE, Baiz PM, Pinho ST. Numerical analysis of size effects on open-hole tensile composite laminates. Compos Part A-Appl S $2013 ; 47: 52-62$.

[40] Erçin GH, Camanho PP, Xavier J, Catalanotti G, Mahdi S, Linde P. Size effects on the tensile and compressive failure of notched composite laminates. Compos Struct 2013;96:736-44.

[41] Arteiro A, Catalanotti G, Xavier J, Camanho PP. Notched response of non-crimp fabric thin-ply laminates. Compos Sci Technol 2013;79:97-114.

[42] Furtado C, Arteiro A, Catalanotti G, Xavier J, Camanho PP. Selective ply-level hybridisation for improved notched response of composite laminates. Compos Struct 2016;145:1-14. 
[43] Arteiro A, Catalanotti G, Xavier J, Linde P, Camanho PP. A strategy to improve the structural performance of non-crimp fabric thin-ply laminates. Compos Struct 2018;188:438-49.

[44] Lavoie JA, Soutis C, Morton J. Apparent strength scaling in continuous fiber composite laminates. Compos Sci Technol 2000;60:283-99.

[45] Wisnom MR, Khan B, Hallett SR. Size effects in unnotched tensile strength of unidirectional and quasi-isotropic carbon/epoxy composites. Compos Struct 2008;84:21-8.

[46] Lee J, Soutis C. Measuring the notched compressive strength of composite laminates: Specimen size effects. Compos Sci Technol 2008;68:2359-66.

[47] Soutis C, Lee J. Scaling effects in notched carbon fibre/epoxy composites loaded in compression. J Mater Sci 2008;43:6593-8.

[48] Green BG, Wisnom MR, Hallett SR. An experimental investigation into the tensile strength scaling of notched composites. Compos Part A-Appl S 2007;38:867-78.

[49] Wisnom MR, Hallett SR. The role of delamination in strength, failure mechanisms and hole size effect in open hole tensile tests on quasi-isotropic laminates. Compos Part A-Appl S 2009;40:335-42.

[50] Wisnom MR, Hallett SR, Soutis C. Scaling effects in notched composites. J Compos Mater 2010;44(10):195-210.

[51] Hitchen SA, Kemp RMJ. The effect of stacking sequence on impact damage in a carbon fibre/epoxy composite. Composites 1995;26:207-14.

[52] Fuoss E, Straznicky PV, Poon C. Effects of stacking sequence on the impact resistance in composite laminates - Part 1: parametric study. Compos Struct 1998;41:67-77.

[53] de Freitas M, Reis L. Failure mechanisms on composite specimens subjected to compression after impact. Compos Struct 1998;42:365-73. 
[54] González EV, Maimí P, Camanho PP, Lopes CS, Blanco N. Effects of ply clustering in laminated composite plates under low-velocity impact loading. Compos Sci Technol 2011;71:805-17.

[55] Sebaey TA, González EV, Lopes CS, Blanco N, Costa J. Damage resistance and damage tolerance of dispersed CFRP laminates: Effect of ply clustering. Compos Struct 2013;106:96-103.

[56] García-Moreno I, Caminero MA, Rodriguez GP. Effects of laminate thickness and ply-stacking sequence on the low velocity impact resistance of carbon fiber-reinforced laminates. Materiales Compuestos 2017;1(1):3544.

[57] Saito H, Morita M, Kawabe K, Kanesaki M, Takeuchi H, Tanaka M, et al. Effect of ply-thickness on impact damage morphology in CFRP laminates. J Reinf Plast Comp 2011;30:1097-106.

[58] Sasikumar A, Trias D, Costa J, Blanco N, Orr J, Linde P. Effect of ply thickness and ply level hybridization on the compression after impact strength of thin laminates. Compos Part A-Appl S 2019;121:232-43.

[59] Sasikumar A, Trias D, Costa J, Blanco N, Orr J, Linde P. Impact and compression after impact response in thin laminates of spread-tow woven and non-crimp fabrics. Compos Struct 2019;215:432-45.

[60] Sasikumar A, Trias D, Costa J, Singery V, Linde P. Mitigating the weak impact response of thin-ply based thin laminates through an unsymmetrical laminate design incorporating intermediate grade plies. Compos Struct 2019;220:93-104.

[61] Nixon-Pearson OJ, Hallett SR, Withers PJ, Rouse J. Damage development in open-hole composite specimens in fatigue. Part 1: Experimental investigation. Compos Struct 2013;106:882-9. 
[62] Nishikawa Y, Okubo K, Fujii T, Kawabe K. Fatigue crack constraint in plain-woven CFRP using newly-developed spread tows. Int J Fatigue $2006 ; 28: 1248-53$.

[63] Moon JB, Kim MG, Kim CG, Bhowmik S. Improvement of tensile properties of CFRP composites under LEO space environment by applying MWNTs and thin-ply. Compos Part A-Appl S 2011;42:694-701.

[64] Yamashita S, Sonehara T, Takahashi J, Kawabe K, Murakami T. Effect of thin-ply on damage behaviour of continuous and discontinuous carbon fibre reinforced thermoplastics subjected to simulated lightning strike. Compos Part A-Appl S 2017;95:132-40.

[65] Yamashita S, Hirano Y, Sonehara T, Takahashi J, Kawabe K, Murakami T. Residual mechanical properties of carbon fibre reinforced thermoplastics with thin-ply prepreg after simulated lightning strike. Compos Part A-Appl S 2017;101:185-94.

[66] Saito H, Takeuchi H, Kimpara I. Experimental evaluation of the damage growth restraining in $90^{\circ}$ layer of thin-ply CFRP cross-ply laminates. Adv Compos Mater 2012;21:57-66.

[67] Sebaey TA, Costa J, Maimí P, Batista Y, Blanco N, Mayugo JA. Measurement of the in situ transverse tensile strength of composite plies by means of the real time monitoring of microcracking. Compos Part B-Eng 2014;65:40-6.

[68] Yokozeki T, Aoki T, Ogasawara T, Ishikawa T. Effects of layup angle and ply thickness on matrix crack interaction in contiguous plies of composite laminates. Compos Part A-Appl S 2005;36:1229-35.

[69] Camanho PP, Dávila CG, Pinho ST, Iannucci L, Robinson P. Prediction of in situ strengths and matrix cracking in composites under transverse tension and in-plane shear. Compos Part A-Appl S 2006;37:165-76. 
[70] Adolfsson E, Gudmundson P. Matrix crack initiation and progression in composite laminates subjected to bending and extension. Int J Solids Struct 1999;36:3131-69.

[71] Andersons J, Joffe R, Spārniņš E, Rubenis O. Progressive cracking mastercurves of the transverse ply in a laminate. Polym Composite 2009;30(8):1175-82.

[72] Saito H, Takeuchi H, Kimpara I. A study of crack suppression mechanism of thin-ply carbon-fiber-reinforced polymer laminate with mesoscopic numerical simulation. J Compos Mater 2014;48(17):2085-96.

[73] Arteiro A, Catalanotti G, Melro AR, Linde P, Camanho PP. Micromechanical analysis of the in situ effect in polymer composite laminates. Compos Struct 2014;116:827-40.

[74] Chang FK, Chen MH. The in situ ply shear strength distribution in graphite/epoxy laminated composites. J Compos Mater 1987;21:708-33.

[75] Catalanotti G. Prediction of in situ strengths in composites: Some considerations. Compos Struct 2019;207:889-93.

[76] Herakovich CT. Influence of layer thickness on the strength of angle-ply laminates. J Compos Mater 1982;16:216-27.

[77] Catalanotti G, Camanho PP, Marques AT. Three-dimensional failure criteria for fiber-reinforced laminates. Compos Struct 2013;95:63-79.

[78] Camanho PP, Arteiro A, Catalanotti G, Melro AR, Vogler M. Threedimensional invariant-based failure criteria for transversely isotropic fibrereinforced composites. In: Camanho PP, Hallett SR, editors. Numerical Modelling of Failure in Advanced Composite Materials; chap. 5. Cambridge: Woodhead Publishing; 2015, p. 111-50.

[79] Olsson R. Analytical prediction of damage due to large mass impact on thin ply composites. Compos Part A-Appl S 2015;72:184-91. 
[80] Bhudolia SK, Joshi SC, Boon YD. Experimental and microscopic investigation on mechanical performance of textile spread-tow thin ply composites. Fiber Polym 2019;20(5):1036-45.

[81] Arteiro A, Catalanotti G, Melro AR, Linde P, Camanho PP. Micromechanical analysis of the effect of ply thickness on the transverse compressive strength of polymer composites. Compos Part A-Appl S 2015;79:127-37.

[82] Fuller J, Wisnom MR. Pseudo-ductility and damage suppression in thin ply CFRP angle-ply laminates. Compos Part A-Appl S 2015;69:64-71.

[83] Yokozeki T, Aoki T, Ishikawa T. Transverse crack propagation in the specimen width direction of CFRP laminates under static tensile loadings. J Compos Mater 2002;36(17):2085-99.

[84] Chang KY, Liu S, Chang FK. Damage tolerance of laminated composites containing an open hole subjected to tensile loadings. J Compos Mater 1991;25:274-301.

[85] Huchette C. Sur la complémentarité des approches expérimentales et numériques pour la modélisation des mécanismes d'endommagement des composites stratifiés. Ph.D. thesis; Université Paris 6; Paris; 2005. In French.

[86] Pierron F, Green B, Wisnom MR. Full-field assessment of the damage process of laminated composite open-hole tensile specimens. Part I: Methodology. Compos Part A-Appl S 2007;38:2307-20.

[87] Pierron F, Green B, Wisnom MR, Hallett SR. Full-field assessment of the damage process of laminated composite open-hole tensile specimens. Part II: Experimental results. Compos Part A-Appl S 2007;38:2321-32.

[88] Laurin F, Carrere N, Huchette C, Maire JF. A multiscale hybrid approach for damage and final failure predictions of composite structures. J Compos Mater 2013;47(20-21):2713-47. 
[89] Ho YC, Sasayama H, Yanagimoto J. Mechanical properties and drawing process of multilayer carbon-fiber-reinforced plastic sheets with various prepreg thicknesses. Adv Mech Engng 2017;9(3):1-12.

[90] Sasayama H, Kawabe K, Tomoda S, Ohsawa I, Kageyama K, Ogata N. Effect of lamina thickness on first ply failure in multidirectionally laminated composites. J Jpn Soc Compos Mater 2004;30(4):142-8. In Japanese.

[91] Takagi K, Nakatani H, Suga K, Koike A, Ogihara S. Effect of ply thickness on mechanical property of CFRP symmetric angle-ply laminates. In: Proceedings of ICCM-18. Jeju Island; 2011, p. 1-4.

[92] Ogihara S, Nakatani H. Effect of ply thickness on mechanical properties in CFRP angle-ply laminates. In: Proceedings of ECCM15. Venice; 2012, p. $1-6$.

[93] Kohler S, Cugnoni J, Amacher R, Botsis J. Transverse cracking in the bulk and at the free edge of thin-ply composites: Experiments and multiscale modelling. Compos Part A-Appl S 2019;124:105468.

[94] Fernberg P, Joffe R. Thin-ply effects on long-term thermal stability of high temperature polyimide composites. In: Proceedings of ICCM-22. Melbourne; 2019, p. 1-2.

[95] Guillamet G. Improved delamination resistance of thin-ply based laminates: an experimental and numerical study. Ph.D. thesis; Universitat de Girona; Girona; 2016.

[96] Chang FK, Scott RA, Springer GS. The effect of laminate configuration on characteristic lengths and rail shear strength. J Compos Mater 1984;18:290-6.

[97] Liu H, Falzon BG, Catalanotti G. Studies on the effects of lamina thickness and orientation on the shear response of composite laminates. In: Proceedings of ICCM-21. Xi'an; 2017, p. 1-10. 
[98] Kawabe K, Sasayama H, Kageyama K, Ogata N. Effect of ply thickness on compressive properties in multidirectionally laminated composites. J Jpn Soc Compos Mater 2008;34:173-81. In Japanese.

[99] Arteiro A, Catalanotti G, Reinoso J, Linde P, Camanho PP. Simulation of the mechanical response of thin-ply composites: From computational micro-mechanics to structural analysis. Arch Computat Methods Eng; 2018. https://doi.org/10.1007/s11831-018-9291-2.

[100] Reis L, de Freitas M. Damage growth analysis of low velocity impacted composite panels. Compos Struct 1997;38(1-4):509-15.

[101] Aoki Y, Suemasu H, Ishikawa T. Damage propagation in CFRP laminates subjected to low velocity impact and static indentation. Adv Compos Mater 2007;16:45-61.

[102] Lopes CS, Seresta O, Coquet Y, Gürdal Z, Camanho PP, Thuis B. Lowvelocity impact damage on dispersed stacking sequence laminates. Part I: Experiments. Compos Sci Technol 2009;69:926-36.

[103] París F, Blázquez A, McCartney LN, Barroso A. Characterization and evolution of matrix and interface related damage in $[0 / 90]_{S}$ laminates under tension. Part II: Experimental evidence. Compos Sci Technol 2010;70:1176-83.

[104] Dávila CG, Camanho PP. Analysis of the effects of residual strains and defects on skin/stiffner debonding using decohesion elements. Tech. Rep. AIAA Paper 2003-1465; NASA Langley Research Center; Hampton, Virginia; 2003.

[105] Lavoie JA, Adolfsson E. Stitch cracks in constraint plies adjacent to a cracked ply. J Compos Mater 2001;35(23):2077-97.

[106] Zubillaga L, Turon A, Maimí P, Costa J, Mahdi S, Linde P. An energy based failure criterion for matrix crack induced delamination in laminated composite structures. Compos Struct 2014;112:339-44. 
[107] Hajikazemi M, Van Paepegem W. Variational analysis of free-edge stress and displacement fields in general un-symmetric and thin-ply laminates under in-plane, bending and thermal loading. Compos Part A-Appl S 2018;113:220-32.

[108] García-Rodríguez SM, Costa J, Singery V, Sasikumar A. A 3D tomographic investigation to elucidate how thin-ply laminates improve the interlaminar shear strength and the effect of toughening the interfaces with veils. In: Proceedings of the 10th European Solid Mechanics Conference. Bologna; 2018, p. 1.

[109] Arca MA. Strengtheninh of L-shaped composite laminates using carbon nanotube reinforcement and thin ply non-crimp fabrics. Master's thesis; Graduate School of Natural and Applied Sciences, Middle East Techincal University; Ankara; 2014.

[110] Furtado C, Arteiro A, Bessa MA, Wardle BL, Camanho PP. Prediction of size effects in open-hole laminates using only the Young's modulus, the strength, and the $\mathcal{R}$-curve of the $0^{\circ}$ ply. Compos Part A-Appl S 2017;101:306-17.

[111] Reinoso J, Arteiro A, Paggi M, Camanho PP. Strength prediction of notched thin ply laminates using finite fracture mechanics and the phase field approach. Compos Sci Technol 2017;150:205-16.

[112] Kötter B, Polyak D, Körbelin J, Fiedler B. Influence of ply thickness on failure initiation, propagation and mechanical properties in CFRP laminates. In: Proceedings of ICFC 7. Vicenza; 2018, p. 1-10.

[113] Cugnoni J, Amacher R, Kohler S, Brunner J, Kramer E, Dransfeld C, et al. Towards aerospace grade thin-ply composites: Effect of ply thickness, fibre, matrix and interlayer toughening on strength and damage tolerance. Compos Sci Technol 2018;168:467-77. 
[114] Laffan MJ, Pinho ST, Robinson P, Iannucci L. Measurement of the in situ ply fracture toughness associated with mode I fibre tensile failure in FRP. Part I: Data reduction. Compos Sci Technol 2010;70:606-13.

[115] Catalanotti G, Xavier J, Camanho PP. Measurement of the compressive crack resistance curve of composites using the size effect law. Compos Part A-Appl S 2014;56:300-7.

[116] Catalanotti G, Arteiro A, Hayati M, Camanho PP. Determination of the mode I crack resistance curve of polymer composites using the size-effect law. Engng Fract Mech 2014;118:49-65.

[117] Catalanotti G, Xavier J. Measurement of the mode II intralaminar fracture toughness and R-curve of polymer composites using a modified Iosipescu specimen and the size effect law. Engng Fract Mech 2015;138:202-14.

[118] Maimí P, Camanho PP, Mayugo JA, Dávila CG. A continuum damage model for composite laminates: Part I - Constitutive model. Mech Mater 2007;39:897-908.

[119] Maimí P, Camanho PP, Mayugo JA, Dávila CG. A continuum damage model for composite laminates: Part II - Computational implementation and validation. Mech Mater 2007;39:909-19.

[120] Dávila CG, Rose CA, Camanho PP. A procedure for superposing linear cohesive laws to represent multiple damage mechanisms in the fracture of composites. Int J Fract 2009;158:211-23.

[121] Camanho PP, Bessa MA, Catalanotti G, Vogler M, Rolfes R. Modeling the inelastic deformation and fracture of polymer composites - Part II: Smeared crack model. Mech Mater 2013;59:36-49.

[122] Arteiro A, Catalanotti G, Xavier J, Camanho PP. Large damage capability of non-crimp fabric thin-ply laminates. Compos Part A-Appl S 2014;63:110-22. 
[123] Pinho ST, Robinson P, Iannucci L. Fracture toughness of the tensile and compressive fiber failure modes in laminated composites. Compos Sci Technol 2006;66:2069-79.

[124] Catalanotti G, Camanho PP, Xavier J, Dávila CG, Marques AT. Measurement of resistance curves in the longitudinal failure of composites using digital image correlation. Compos Sci Technol 2010;70:1986-93.

[125] Laffan MJ, Pinho ST, Robinson P, McMillan AJ. Translaminar fracture toughness testing of composites: A review. Polym Test 2012;31:481-9.

[126] Ortega A, Maimí P, González EV, Trias D. Characterization of the translaminar fracture Cohesive Law. Compos Part A-Appl S 2016;91:5019.

[127] Ortega A, Maimí P, González EV, Trias D. Specimen geometry and specimen size dependence of the $\mathcal{R}$-curve and the size effect law from a cohesive model point of view. Compos Part A-Appl S 2017;205:239-54.

[128] Walker TH, Avery WB, Ilcewicz LB, Poe, Jr. CC, Harris CE. Tension fracture of laminates for transport fuselage. Part I: material screening. In: Soderquist JR, Neri LM, Bohon HL, editors. Proceedings of the 9th DoD/NASA/FAA conference on fibrous composites in structural design; vol. II. Lake Tahoe, Nevada; 1991, p. 747-87.

[129] Coats TW, Harris CE. A progressive damage methodology for residual strength predictions of notched composite panels. Tech. Rep. NASA/TM1998-207646; NASA Langley Research Center; Hampton, Virginia; 1998.

[130] Coats TW, Harris CE. A progressive damage methodology for residual strength predictions of notched composite panels. J Compos Mater 1999;33(23):2193-224.

[131] Caminero MA, Lopez-Pedrosa M, Pinna C, Soutis C. Damage monitoring and analysis of composite laminates with an open hole and adhe- 
sively bonded repairs using digital image correlation. Compos Part B-Eng 2013;53:76-91.

[132] Bergan AC, Dávila CG, Leone FA, Awerbuch J, Tan TM. Mode I cohesive law characterization of through-crack propagation in a multidirectional laminate. Tech. Rep. NF1676L-18222; NASA Langley Research Center; Hampton, Virginia; 2014.

[133] Fernandes MFC. Translaminar fracture of thin-ply composite laminates. Master's thesis; Faculdade de Engenharia, Universidade do Porto; Porto; 2014 .

[134] Bullegas G, Pinho ST, Pimenta S. Engineering the translaminar fracture behaviour of thin-ply composites. Compos Sci Technol 2016;131:110-22.

[135] Bažant ZP, Planas J. Fracture and Size Effect in Concrete and Other Quasibrittle Materials. CRC Press LLC; 1997.

[136] Bažant ZP, Daniel IM, Li Z. Size effect and fracture characteristics of composite laminates. Mater Struct 1996;118:317-24.

[137] Bažant ZP, Kim JK, Pfeiffer PA. Nonlinear fracture properties from size effect tests. J Struct Eng-ASCE 1986;112:289-307.

[138] Bažant ZP. Size effect on structural strength: a review. Arch Appl Mech 1999;69:703-25.

[139] Bažant ZP, Yavari A. Is the cause of size effect on structural strength fractal or energetic-statistical? Engng Fract Mech 2005;72:1-31.

[140] Camanho PP, Catalanotti G. On the relation between the mode I fracture toughness of a composite laminate and that of a $0^{\circ}$ ply: Analytical model and experimental validation. Engng Fract Mech 2011;78:2535-46.

[141] CMH-17-3G . Composite Materials Handbook; vol. 3 of 6: Polymer Matrix Composites Materials Usage, Design and Analysis. SAE International; 2012 . 
[142] Iarve EV, Mollenhauer D, Kim R. Theoretical and experimental investigation of stress redistribution in open hole composite laminates due to damage accumulation. Compos Part A-Appl S 2005;36:163-71.

[143] Wisnom MR. Size effects in the testing of fibre-composite materials. Compos Sci Technol 1999;59:1937-57.

[144] Bažant ZP. Size effect. Int J Solids Struct 2000;37:69-80.

[145] Hallett SR, Green BG, Jiang WG, Wisnom MR. An experimental and numerical investigation into the damage mechanisms in notched composites. Compos Part A-Appl S 2009;40:613-24.

[146] Lee J, Soutis C. Thickness effect on the compressive strength of T800/924C carbon fibre-epoxy laminates. Compos Part A-Appl S $2005 ; 36: 213-27$.

[147] Camanho PP, Maimí P, Dávila CG. Prediction of size effects in notched laminates using continuum damage mechanics. Compos Sci Technol $2007 ; 67: 2715-27$.

[148] Chang JB, Goyal VK, Klug JC, Rome JI. Composite structures damage tolerance analysis methodologies. Tech. Rep. NASA/CR-2012-217347; NASA Langley Research Center; Hampton, Virginia; 2012.

[149] de Moura MFSF, Gonçalves JPM, Marques AT, de Castro PMST. Modelling compression failure after low velocity impact on laminated composites using interface elements. J Compos Mater 1997;31(15):1462-79.

[150] Richardson MOW, Wisheart MJ. Review of low-velocity impact properties of composite materials. Compos Part A-Appl S 1996;27A:1123-31.

[151] Olsson R, Ahlqvist F, André A, Hellström P, Alvarez E, González EV, et al. Testing and modelling of tension after impact of a thin ply testile composite. In: Proceedings of ECCM17. Munich; 2016, p. 1-8. 
[152] García-Rodríguez SM, Costa J, Bardera A, Singery V, Trias D. A 3D tomographic investigation to elucidate the low-velocity impact resistance, tolerance and damage sequence of thin non-crimp fabric laminates: effect of ply-thickness. Compos Part A-Appl S 2018;113:53-65.

[153] Soto A, González EV, Maimí P, Martín de la Escalera F, Sainz de Aja JR, Alvarez E. Low velocity impact and compression after impact simulation of thin ply laminates. Compos Part A-Appl S 2018;109:413-27.

[154] Yamada K, Yamamoto S, Kanesaki M, Nishikawa M, Matsuda N, Kawabe $\mathrm{K}$, et al. Effect of ply thickness on impact damage modes of thin-ply CFRP laminates. In: Proceedings of ICCM-22. Melbourne; 2019, p. 1-12.

[155] García-Rodríguez SM, Bardera A, Sasikumar A, Ruiz M, Singery V, Boada I, et al. Effect of ply-thickness on the impact response of interleaved thin-ply non-crimp-fabric laminates: X-ray tomography investigation. Materiales Compuestos 2017;1(1):57-64.

[156] García-Rodríguez SM, Costa J, Singery V, Boada I, Mayugo JA. The effect interleaving has on thin-ply non-crimp fabric laminate impact response: X-ray tomography investigation. Compos Part A-Appl S 2018;107:409-20.

[157] Naghipour P, Bartsch M, Voggenreiter H. Simulation and experimental validation of mixed mode delamination in multidirectional $\mathrm{CF} / \mathrm{PEEK}$ laminates under fatigue loading. Int J Solids Struct 2011;48:1070-81.

[158] Allegri G, Wisnom MR. A non-linear damage evolution model for mode II fatigue delamination onset and growth. Int J Fatigue 2012;43:226-34.

[159] Chen WH, Lee SS, Yeh JT. Three-dimensional contact stress analysis of a composite laminate with bolted joint. Compos Struct 1995;30:287-97.

[160] Camanho PP, Matthews FL. Stress analysis and strength prediction of mechanically fastened joints in FRP: a review. Compos Part A-Appl S 1997;28A:529-47. 
[161] Camanho PP, Tavares CML, de Oliveira R, Marques AT, Ferreira AJM. Increasing the efficiency of composite single-shear lap joints using bonded inserts. Compos Part B-Eng 2005;36:372-83.

[162] Camanho PP, Lambert M. A design methodology for mechanically fastened joints in laminated composite materials. Compos Sci Technol 2006;66:3004-20.

[163] Catalanotti G, Camanho PP. A semi-analytical method to predict nettension failure of mechanically fastened joints in composite laminates. Compos Sci Technol 2013;76:69-76.

[164] Standard test method for bearing response of polymer matrix composite laminates, ASTM D5961/D5961M - 13. ASTM International; West Conshohocken, PA, USA; 2013.

[165] Catalanotti G, Camanho PP, Ghys P, Marques AT. Experimental and numerical study of fastener pull-through failure in GFRP laminates. Compos Struct 2011;94:239-45.

[166] Cooper C, Turvey GJ. Effects of joint geometry and bolt torque on the structural performance of single bolt tension joints in pultruded GRP sheet material. Compos Struct 1995;32:217-26.

[167] Camanho PP. Application of numerical methods to the strength prediction of mechanically fastened joints in composite laminates. Ph.D. thesis; Centre for Composite Materials, Imperial College of Science, Technology and Medicine; London; 1999.

[168] Chang FK, Chang KY. Post-failure analysis of bolted composite joints in tension or shear-out mode failure. J Compos Mater 1987;21:809-33.

[169] Garbo SP, Ogonowski JM. Effect of variances and manufacturing tolerances on the design strength and life of mechanically fastened composite joints. Volume 1 - Methodology development and data evaluation. Final report AFWAL-TR-81-3041; Flight Dynamics Laboratory, Air Force 
Wright Aeronautical Laboratories; Air Force Systems Command, WrightPatterson Air Force Base, Ohio; 1981.

[170] Camanho PP, Matthews FL. Delamination onset prediction in mechanically fastened joints in composite laminates. J Compos Mater 1999;33(10):906-27.

[171] Feraboli P, Miller M. Damage resistance and tolerance of carbon/epoxy composite coupons subjected to simulated lightning strike. Compos Part A-Appl S 2009;40:954-67.

[172] Wu H, Li S, Zhang Z, Tong L. Electrical responses of thin-ply composites. In: Proceedings of ICCM-22. Melbourne; 2019, p. 1-8.

[173] Russello M, Diamanti EK, Catalanotti G, Ohlsson F, Hawkins SC, Falzon BG. Enhancing the electrical conductivity of carbon fibre thin-ply laminates with directly grown aligned carbon nanotubes. Compos Struct $2018 ; 206: 272-8$.

[174] El-Dessouky HM. Spread tow technology for ultra lightweight CFRP composites: potential and possibilities. In: Bafekrpour E, editor. Advanced Composite Materials: Properties and Applications; chap. 6. Warsaw: De Gruyter Open; 2017, p. 323-48.

[175] Mouane K. Polyimide thin-ply composite. Master's thesis; Luleå University of Technology, Department of Engineering Sciences and Mathematics; 2018.

[176] Tsai SW. Strength and Life of Composites. Composites Design Group, Department of Aeronautics and Astronautics, Stanford University; 2008.

[177] Tsai SW, Melo JDD. An invariant-based theory of composites. Compos Sci Technol 2014;100:237-43.

[178] Baker N, Butler R, York CB. Damage tolerance of fully orthotropic laminates in compression. Compos Sci Technol 2012;72:1083-9. 
[179] Cadena DSA. Improvement in damage tolerance and buckling behaviour of a composite fuselage panel using thin plies. Master's thesis; Politecnico de Milano, Facoltà di Ingegneria Industriale; Milan; 2014.

[180] Tao J, Sun CT. Influence of ply orientation on delamination in composite laminates. J Compos Mater 1998;32(21):1933-47.

[181] Mencattelli L, Pinho ST. Realising bio-inspired impact damage-tolerant thin-ply CFRP Bouligand structures via promoting diffused sub-critical helicoidal damage. Compos Sci Technol 2019;182:107684.

[182] Fuller J, Wisnom MR. Ductility and pseudo-ductility of thin ply angle-ply CFRP laminates under quasi-static cyclic loading. Compos Part A-Appl S 2018;107:31-8.

[183] Czél G, Wisnom MR. Demonstration of pseudo-ductility in high performance glass/epoxy composites by hybridisation with thin-ply carbon prepreg. Compos Part A-Appl S 2013;52:23-30.

[184] Czél G, Rév T, Jalalvand M, Fotouhi M, Wisnom MR. Demonstration of pseudo-ductility in quasi-isotropic laminates comprising thin-ply UD carbon/epoxy hybrid sub-laminates. In: Proceedings of ECCM17. Munich; 2016, p. 1-8.

[185] Czél G, Jalalvand M, Wisnom MR, Czigány T. Design and characterisation of high performance, pseudo-ductile all-carbon/epoxy unidirectional hybrid composites. Compos Part B-Eng 2017;111:348-56.

[186] Fotouhi M, Jalalvand M, Wisnom MR. High performance quasi-isotropic thin-ply carbon/glass hybrid composites with pseudo-ductile behaviour in all fibre orientations. Compos Sci Technol 2017;152:101-10.

[187] Czél G, Rev T, Jalalvand M, Fotouhi M, Longana ML, Nixon-Pearson OJ, et al. An experimental investigation into the tensile strength scaling of notched composites. Compos Part A-Appl S 2018;104:151-64. 
[188] Fotouhi M, Jalalvand M, Wisnom MR. Notch insensitive orientationdispersed pseudo-ductile thin-ply carbon/glass hybrid laminates. Compos Part A-Appl S 2018;110:29-44.

[189] Cugnoni J, Frossard G, Amacher R, Botsis J. Translaminar fracture of regular and hybrid thin ply composites: experimental characterization and modeling. In: Proceedings of ECCM18. Athens; 2018, p. 1-8.

[190] Wisnom MR, Czél G, Swolfs Y, Jalalvand M, Gorbatikh L, Verpoest I. Hybrid effects in thin ply carbon/glass unidirectional laminates: Accurate experimental determination and prediction. Compos Part A-Appl S 2016;88:131-9.

[191] Ogihara S, Takeda N. Interaction between transverse cracks and delamination during damage progress in CFRP cross-ply laminates. Compos Sci Technol 1995;54:395-404.

[192] Vallmajó O, Cózar IR, Furtado C, Tavares R, Arteiro A, Turon A, et al. Virtual calculation of the B-value allowables of notched composite laminates. Compos Struct 2019;212:11-21.

[193] Amacher R, Cugnoni J, Botsis J. Thin ply composites: experimental characterization and modeling. In: Proceedings of ICCM-19. Montréal; 2013, p. 1-13.

[194] Teixeira RF, Pinho ST, Robinson P. Thickness-dependence of the translaminar fracture toughness: Experimental study using thin-ply composites. Compos Part A-Appl S 2016;90:33-44. 

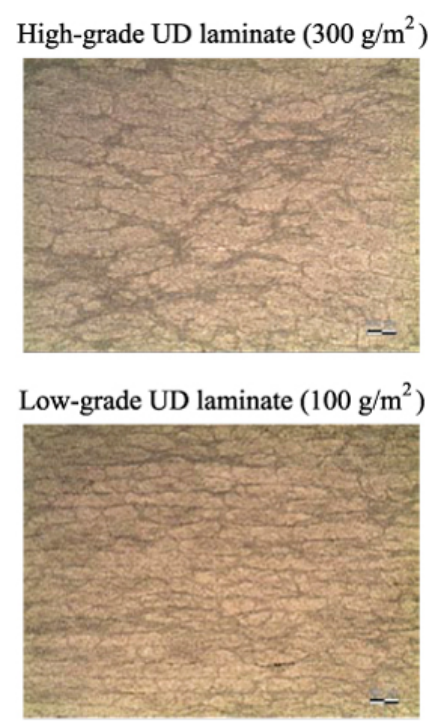

Spread-tow UD laminate $\left(30 \mathrm{~g} / \mathrm{m}^{2}\right)$

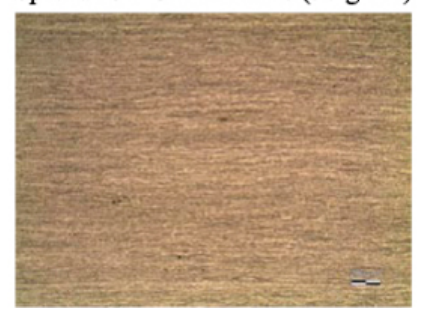

Figure 1: Optical micrographs of carbon fibre/epoxy composites of different grades (after Amacher et al. [193]). 


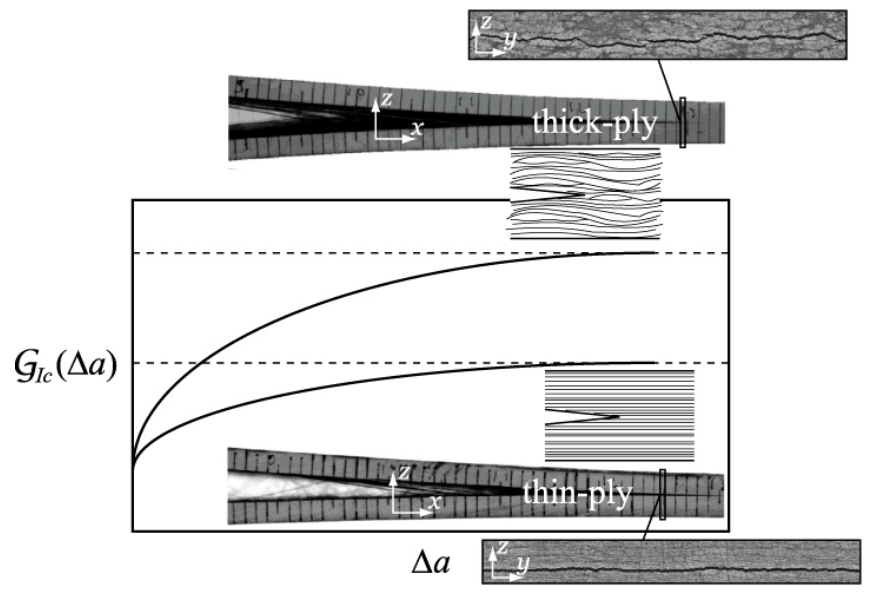

Figure 2: Effect of the uniformity of spread-tow laminae on the crack resistance curve associated with mode I inter-laminar fracture of UD polymer composites (after Frossard et al. $[12])$.

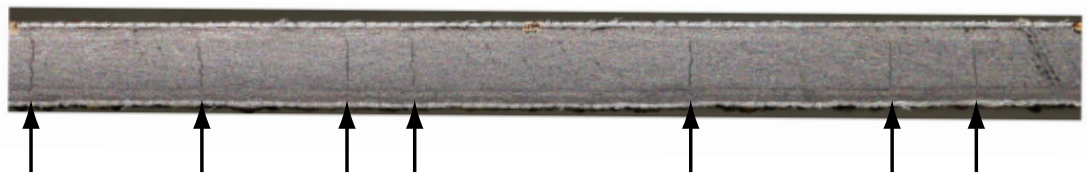

Figure 3: Transverse matrix cracks in a cross-ply laminate (after Sebaey et al. [67]).

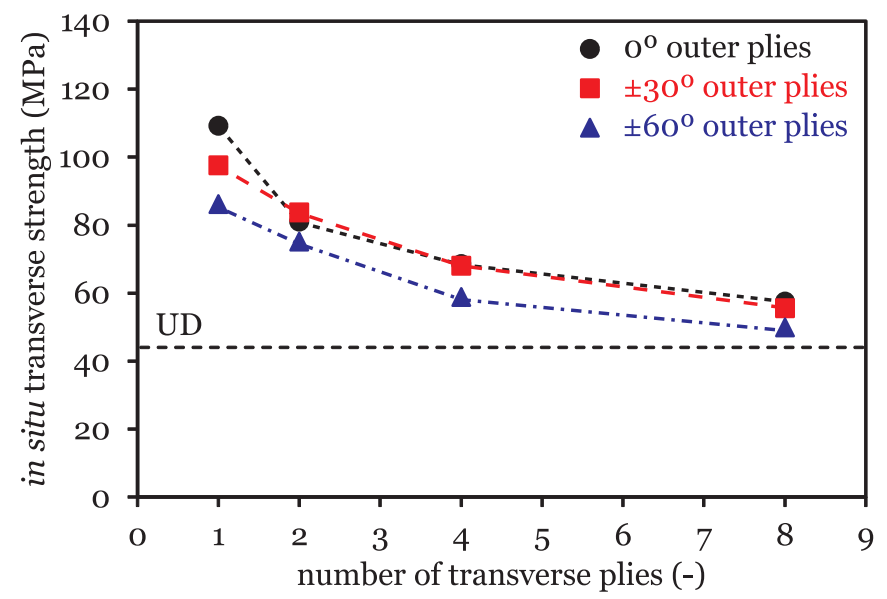

Figure 4: In-situ effect on the transverse tensile strength of an embedded $90^{\circ}$ ply (after Flaggs and Kural [22]). 


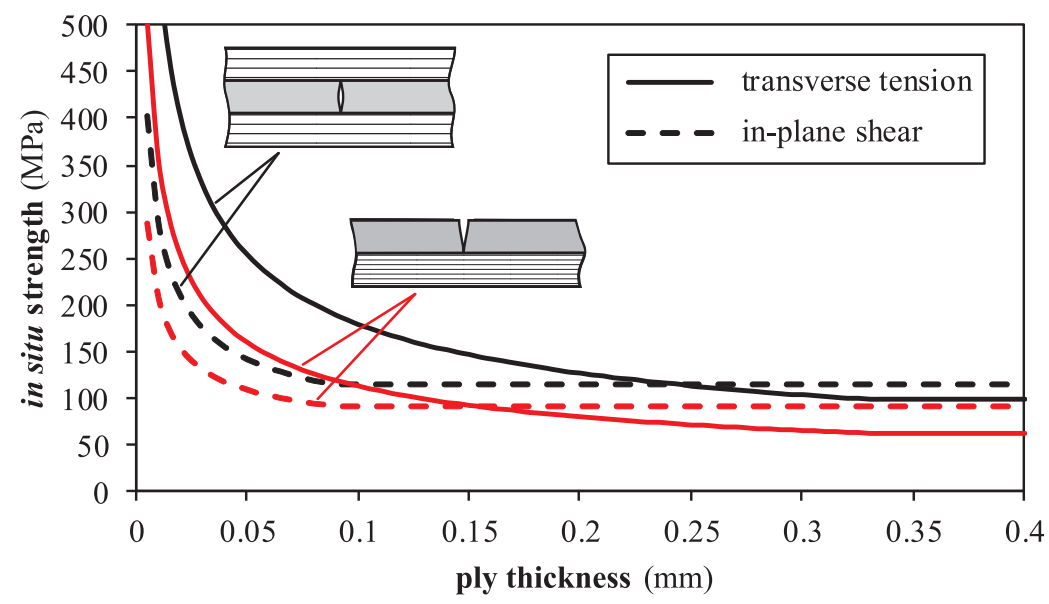

Figure 5: In-situ transverse tensile and in-plane shear strengths of an embedded inner or outer ply (after Camanho et al. [69]).
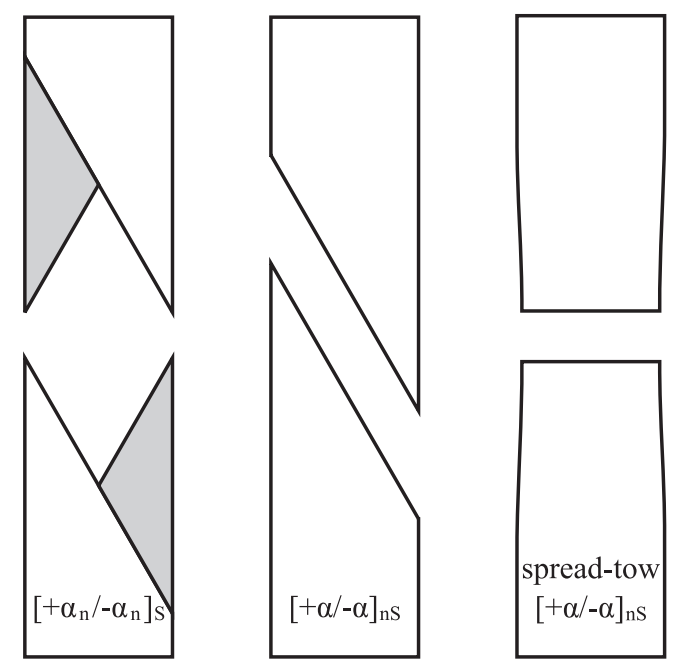

Figure 6: Failure of blocked-ply, dispersed-ply and spread-tow angle-ply laminates (after Herakovich [76] and Fuller and Wisnom [82]). 


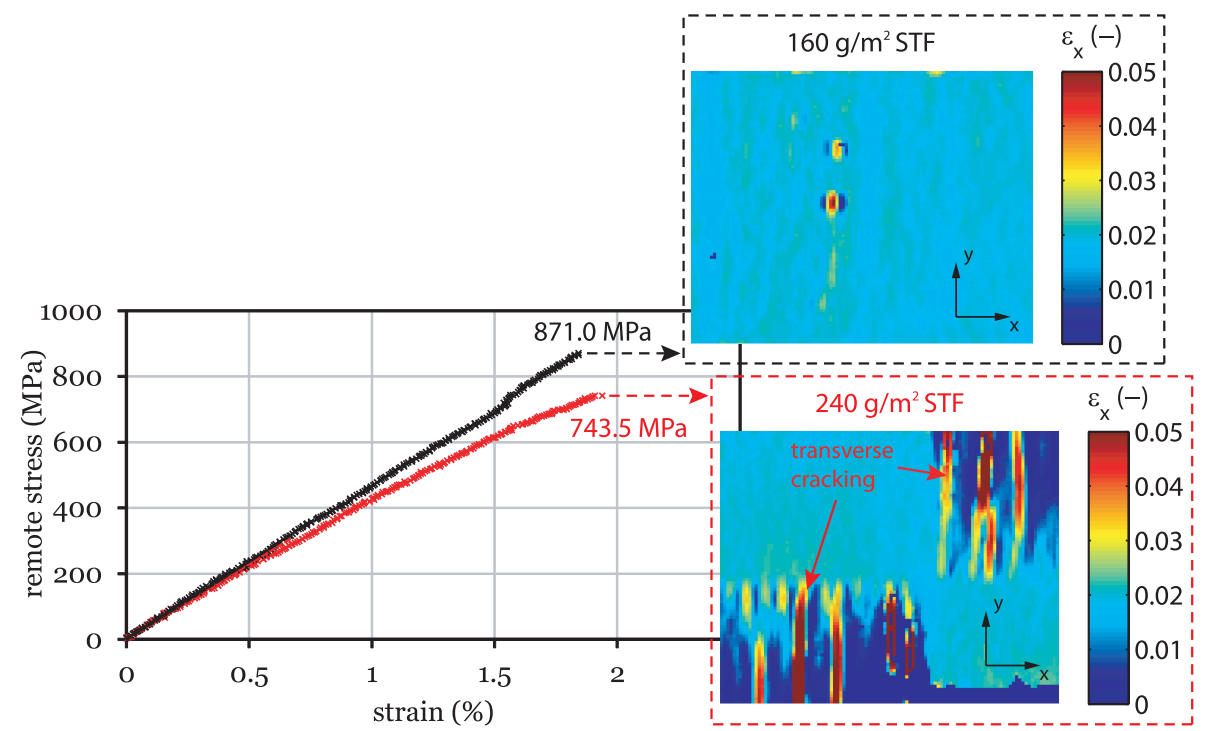

Figure 7: Remote stress-strain relations and longitudinal strain fields $\left(\varepsilon_{x}\right)$ obtained by digital image correlation at the stage prior to ultimate failure in plain weave spread-tow fabrics (after Arteiro et al. [6]). STF stands for spread-tow fabric. Before ultimate failure, no transverse cracks could be observed in the $160 \mathrm{~g} / \mathrm{m}^{2}$ spread-tow fabrics $(\times)$. However, the outer transverse yarns of the $240 \mathrm{~g} / \mathrm{m}^{2}$ spread-tow fabrics developed several matrix cracks that contributed to the nonlinear tensile response of this laminate $(\times)$.

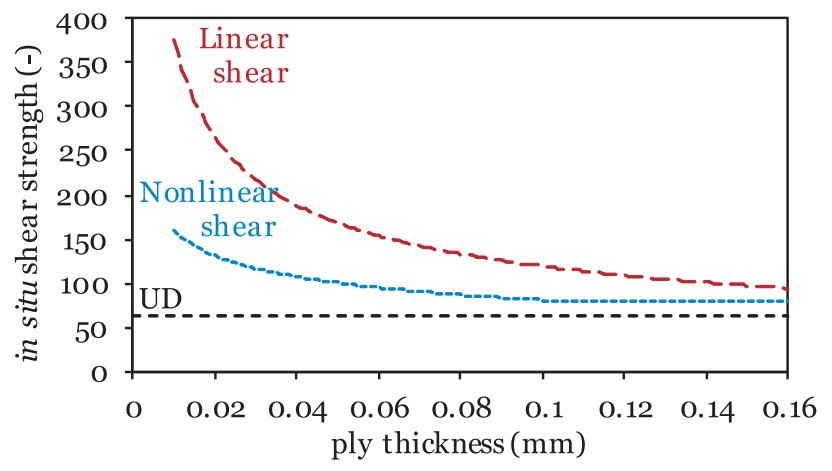

Figure 8: Linear and nonlinear predictions for the in-situ in-plane shear strength of a thin embedded ply (after Camanho et al. [69]). 

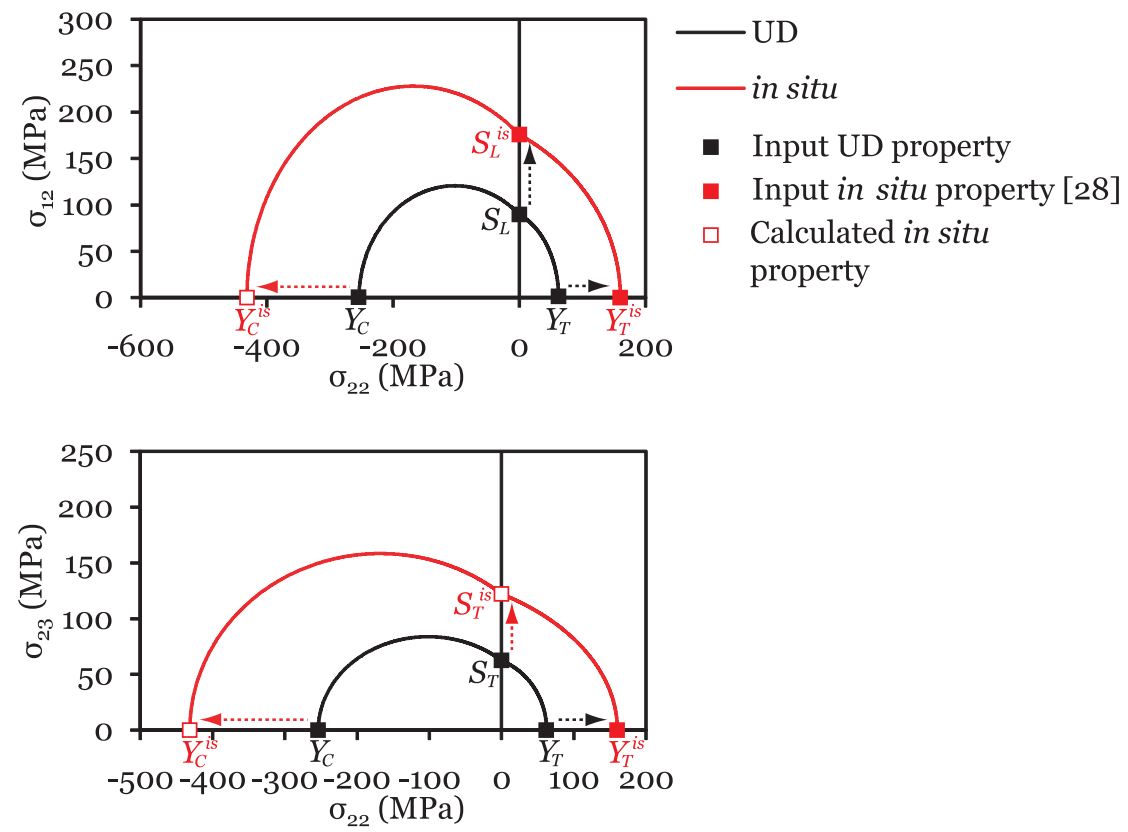

Figure 9: In-situ effect on the failure envelopes for matrix-dominated damage mechanisms (after Camanho et al. [78]).

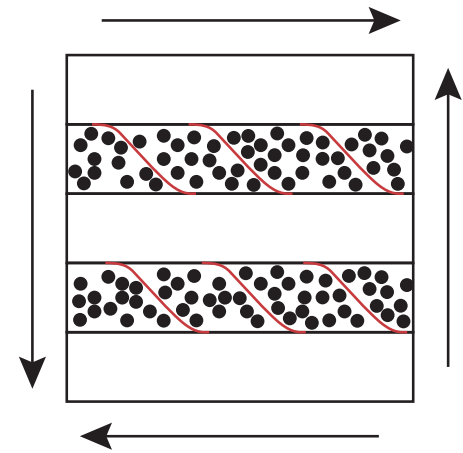

Figure 10: Transverse shear cracking in multi-directional laminates (after Olsson [79]). 


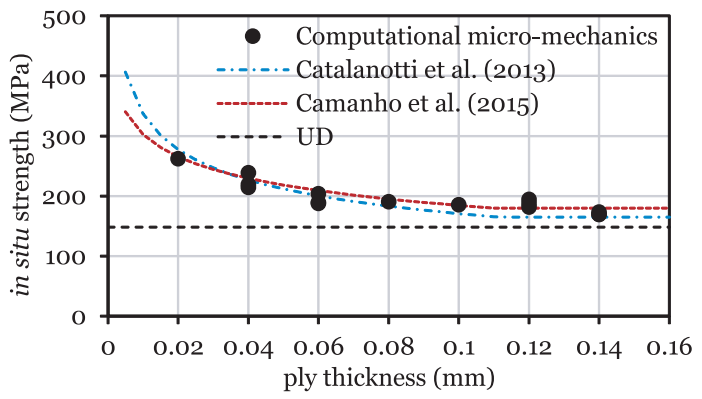

Figure 11: In-situ transverse compressive strength predicted by computational micromechanics and phenomenological failure criteria (after Arteiro et al. [81]).

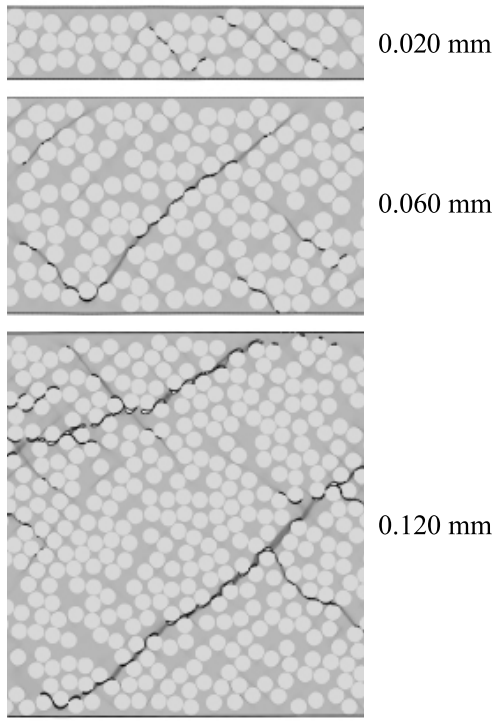

Figure 12: In-situ effect on wedge transverse cracking (after Arteiro et al. [81]). Representative volume elements loaded in compression by a uniaxial remote strain of $2.5 \%$ along the horizontal direction show that failure of conventional $90^{\circ}$ plies is dominated by fibre-matrix interface cracking and large localised plastic deformation in a plane not aligned with the loading direction. Thin plies, on the other hand, show a dispersed damage mechanism, with reduced transverse cracking at the same applied remote strain. 


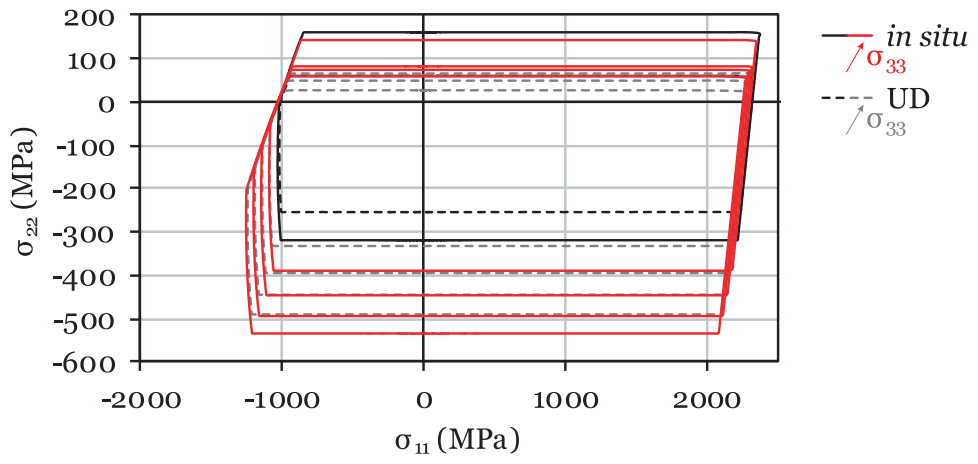

Figure 13: Longitudinal-transverse failure envelopes for different values of applied throughthickness transverse compressive stress $\left(\sigma_{33}\right)$ for an embedded and a UD ply (after Arteiro et al. [99]). Black lines correspond to $\sigma_{33}=0$, and coloured lines to non-zero $\sigma_{33}$. The same value of $\sigma_{33}$ is applied for envelopes in the same position with respect to the reference black lines $\left(\sigma_{33}=0\right)$.

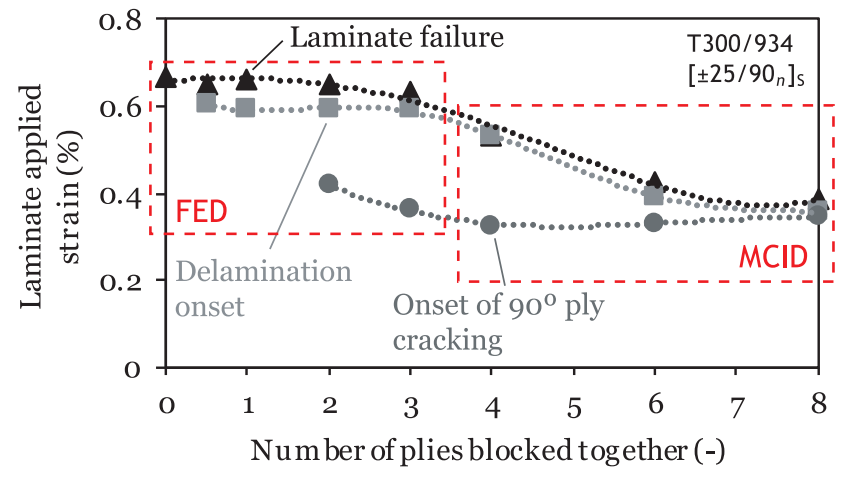

Figure 14: Laminate applied strain at the onset of $90^{\circ}$ ply cracking, at the onset of delamination, and at laminate failure (after O'Brien [26]). In the laminates with 4 or more plies blocked together, delamination is induced by matrix cracking (MCID), whereas in the laminates with less than 3 plies blocked together, delamination starts from the free edges (FED). 


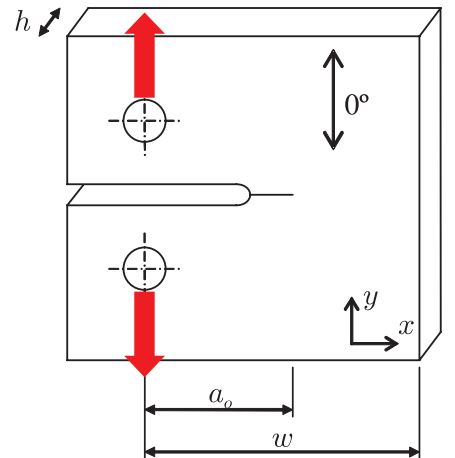

(a) CT specimen

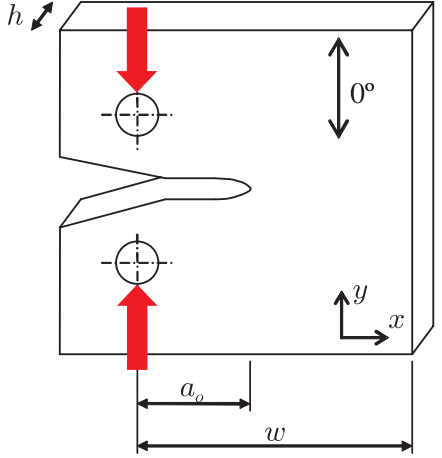

(b) CC specimen.

Figure 15: CT and CC coupon configurations (after Pinho et al. [123]).

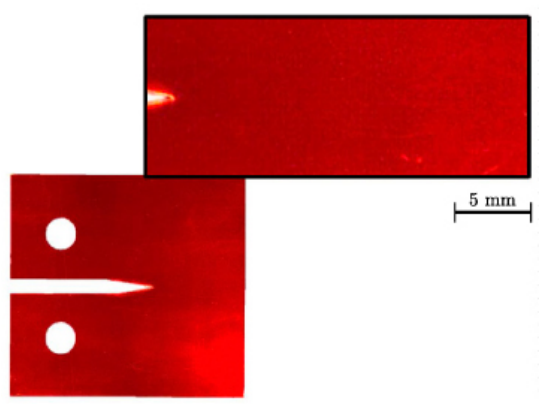

(a) $0.055 \mathrm{~mm}$ dispersed plies prior to the peak load.

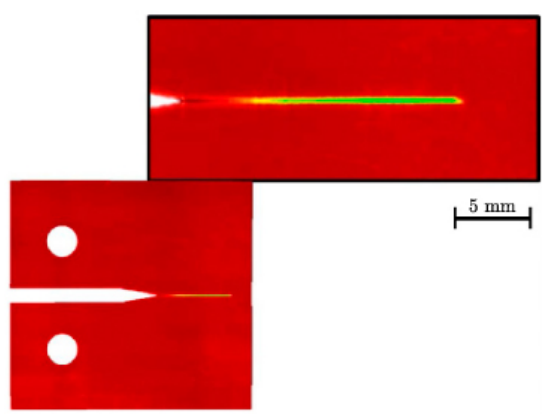

(c) $0.055 \mathrm{~mm}$ dispersed plies after testing.

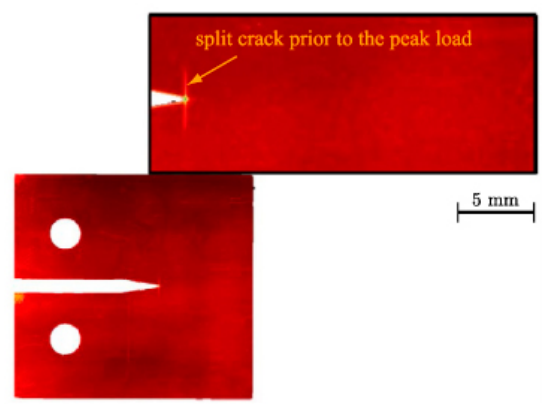

(b) $0.110 \mathrm{~mm}$ blocked plies prior to the peak load.

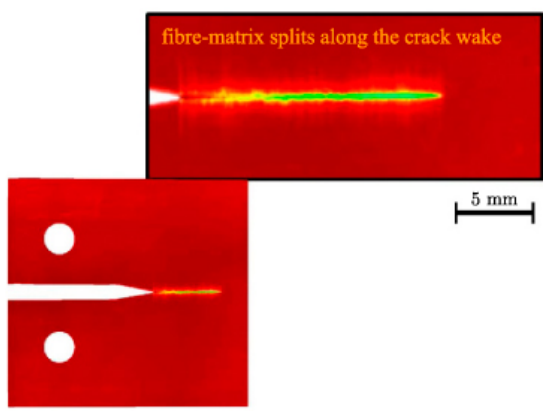

(d) $0.110 \mathrm{~mm}$ blocked plies after testing.

Figure 16: X-ray imaging of $\left[90_{2} /(90 / 0)_{16} / 90\right]_{\mathrm{S}}$ ( $\mathrm{a}$ and c) and $\left[90_{2} /\left(90_{2} / 0_{2}\right)_{8} / 90\right]_{s}$ (b and d) thin-ply CT specimens (after Teixeira et al. [194]). Split cracking is observed in laminates with intermediate ply thickness ( $b$ and d), but it is completely suppressed in laminates with thin plies ( $\mathrm{a}$ and $\mathrm{c}$ ). 


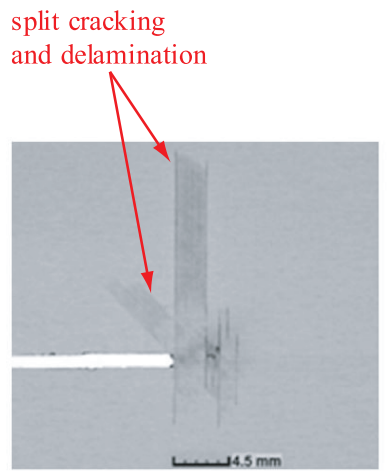

Central $\left[0_{2}\right]$ ply
IM7/8552

$[45 / 90 /-45 / 0]_{4 \mathrm{~s}}$

OCT specimens

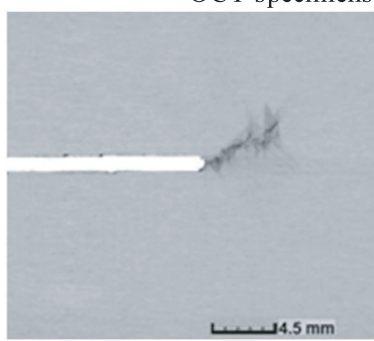

Outboard [0] ply

(a) Split cracking and delamination at the notch tip on the central block of two $0^{\circ}$ plies and on a single $0^{\circ}$ ply of an over-height CT test specimen (after Xu et al. [36]).

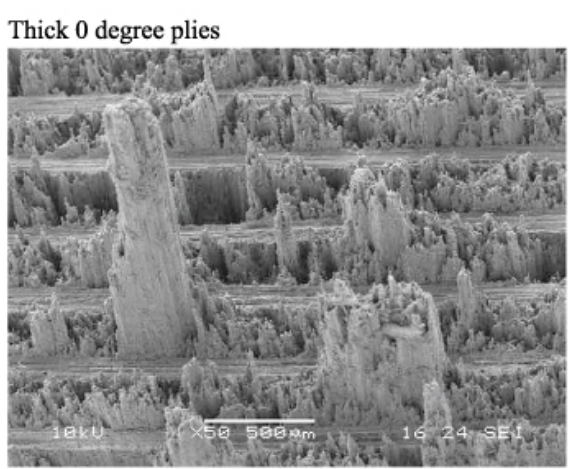

Thin 0 degree plies with

hierarchical pattern of micro-cuts

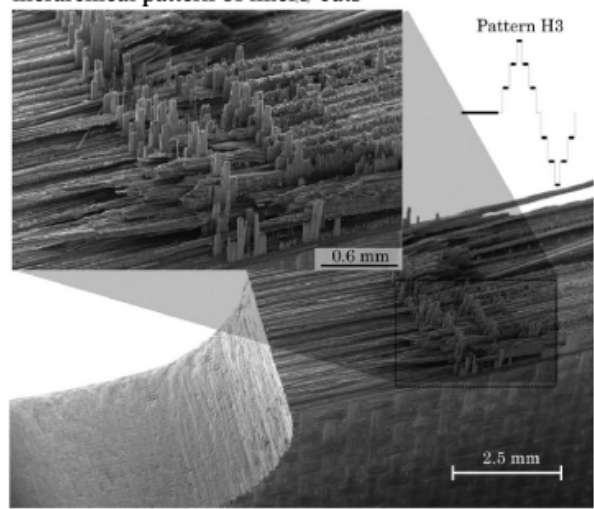

(b) SEM micrograph of fracture surfaces of a thick $0^{\circ}$ ply (after Laffan et al. [37]) and a thin $0^{\circ}$ ply with an hierarchical pattern of micro-cuts (after Bullegas et al. [134]).

Figure 17: Post-mortem observations of intra-laminar fibre fracture. 

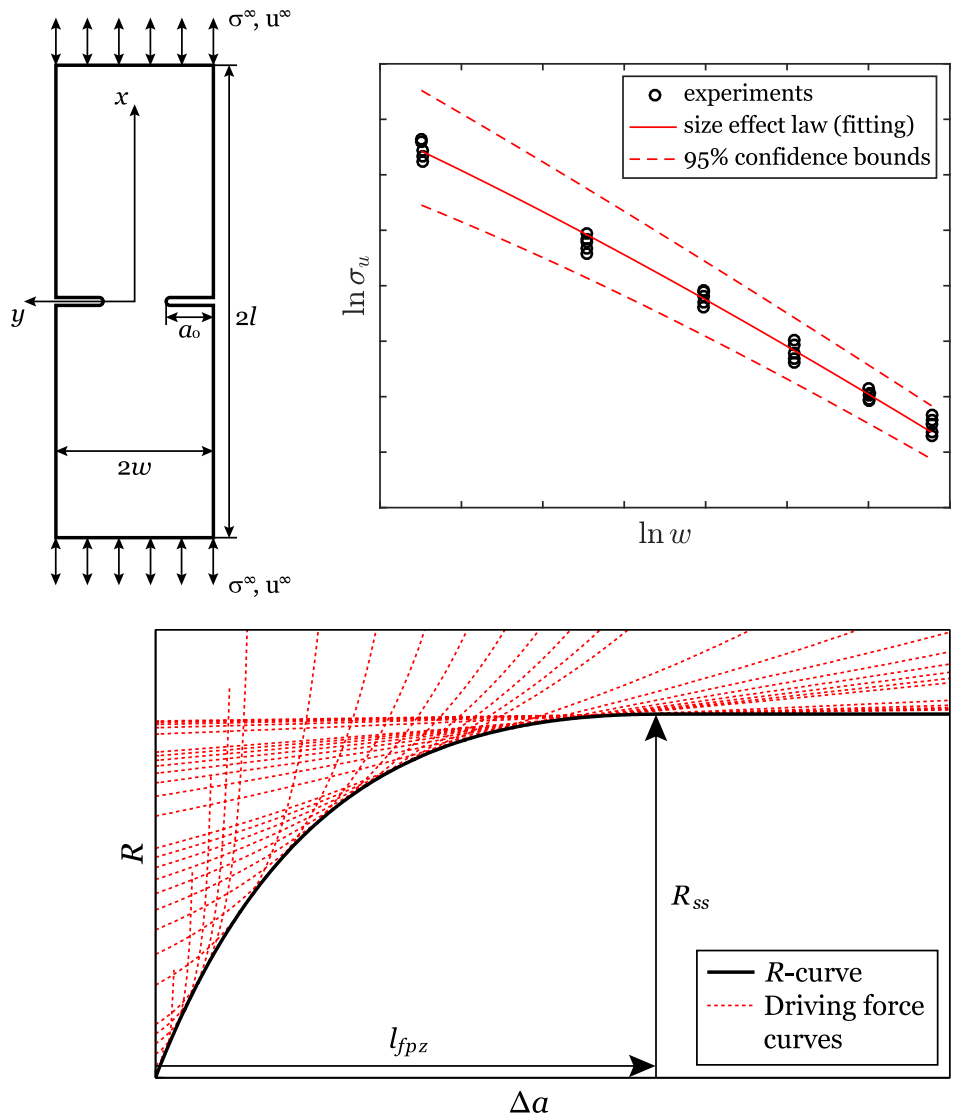

Figure 18: Size effect law fitting and $\mathcal{R}$-curve determined as the envelope of driving force curves (after Catalanotti et al. [116]). 

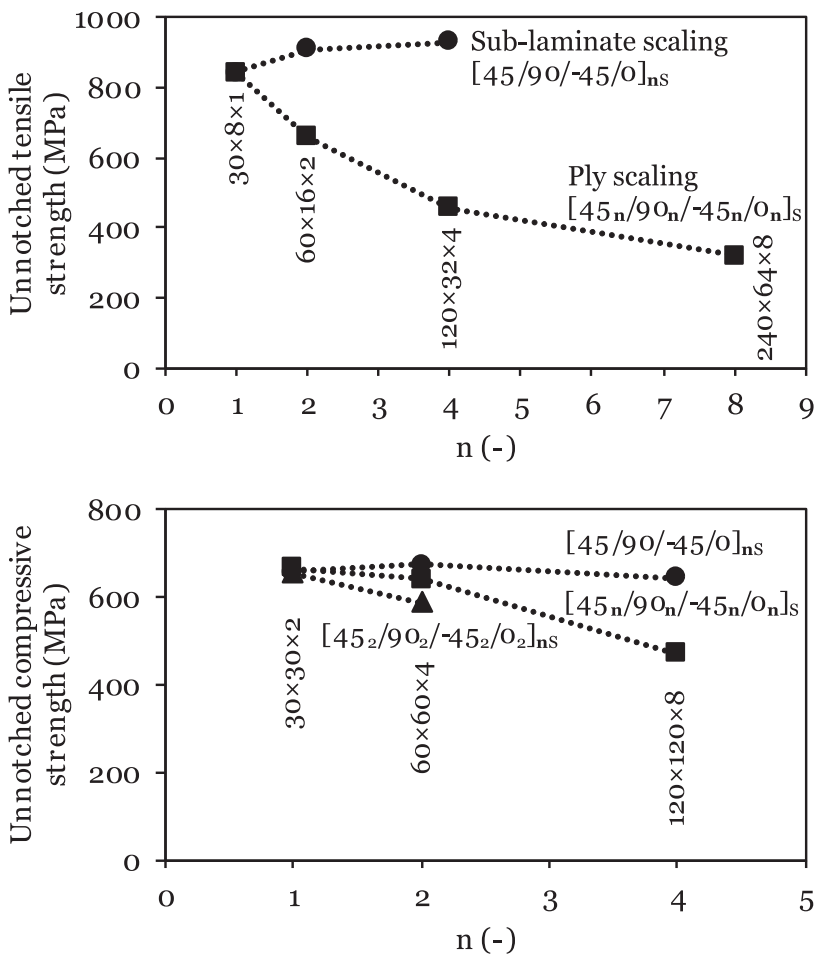

Figure 19: Size effects in un-notched IM7/8552 carbon/epoxy coupons loaded in tension (after Wisnom et al. $[45,50])$ and in compression (after Lee and Soutis [46]). Specimen dimensions are given as: gauge length $(\mathrm{mm}) \times$ width $(\mathrm{mm}) \times$ thickness $(\mathrm{mm})$. 


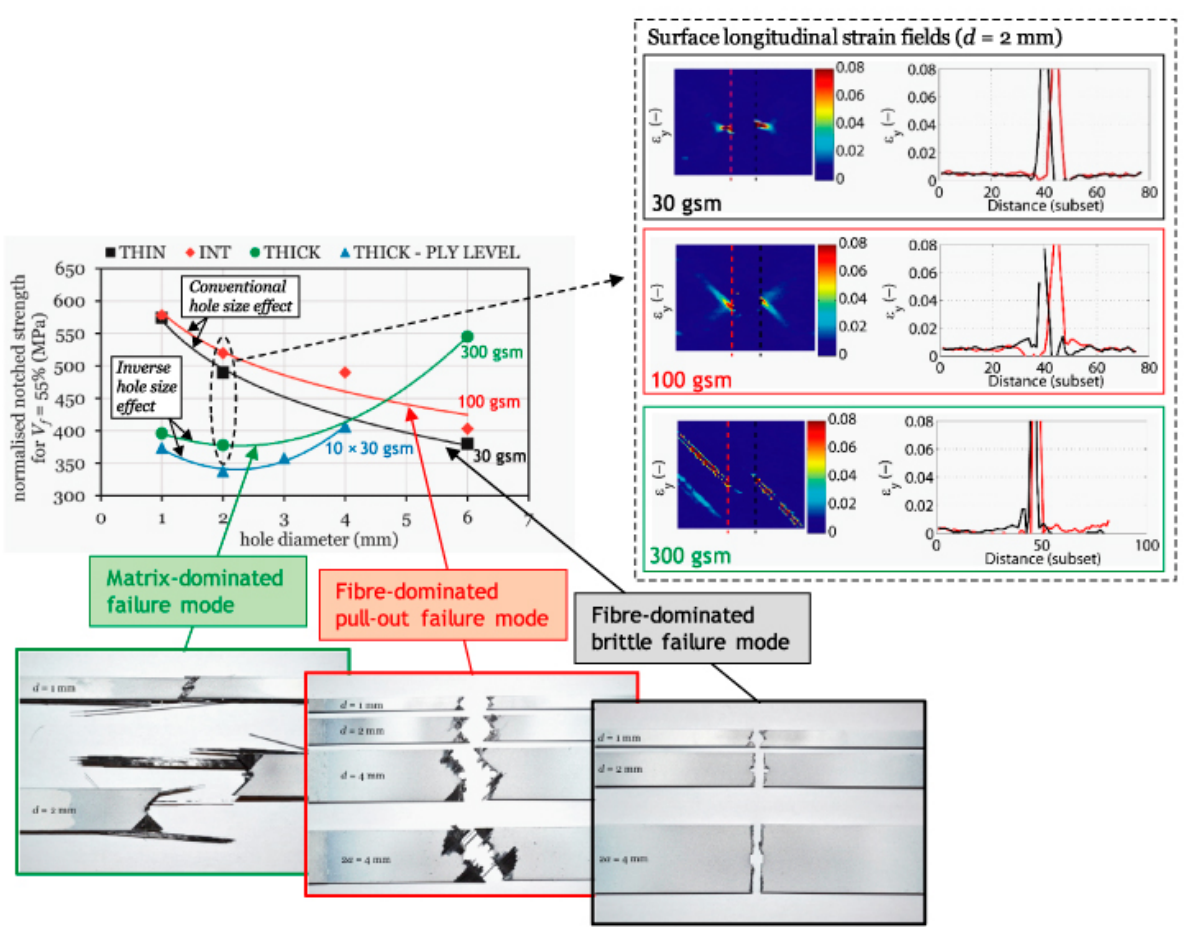

Figure 20: Size effects in notched M40JB/ThinPreg ${ }^{\top M}$ 80EP carbon/epoxy coupons loaded in tension, representative failed specimens, and surface longitudinal strain fields obtained with digital image correlation from specimens with a hole diameter of $2 \mathrm{~mm}$ (after Furtado et al. $[42])$. 


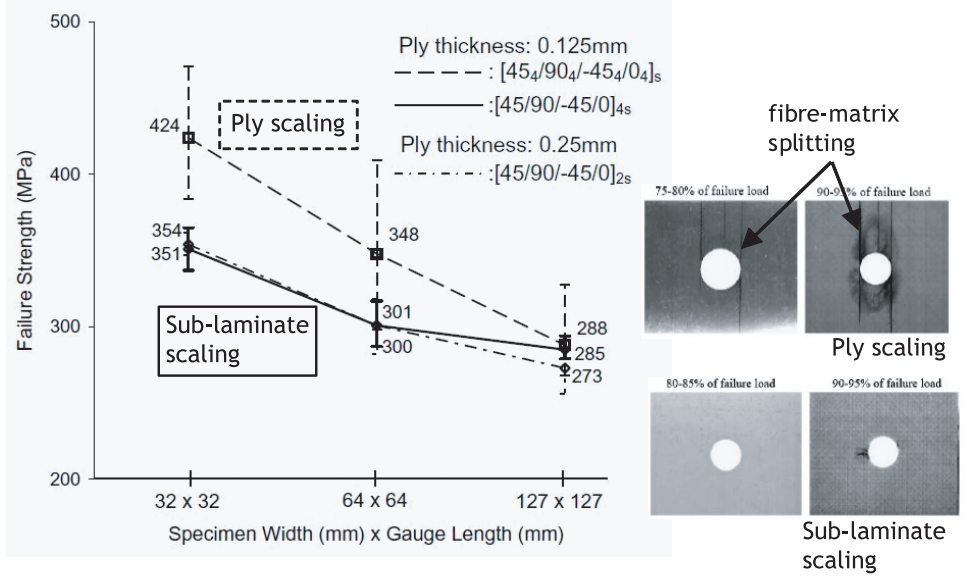

Figure 21: Size effects in notched IM7/8552 carbon/epoxy coupons loaded in compression and damage development in representative open-hole compression specimens (after Lee and Soutis [46]). 

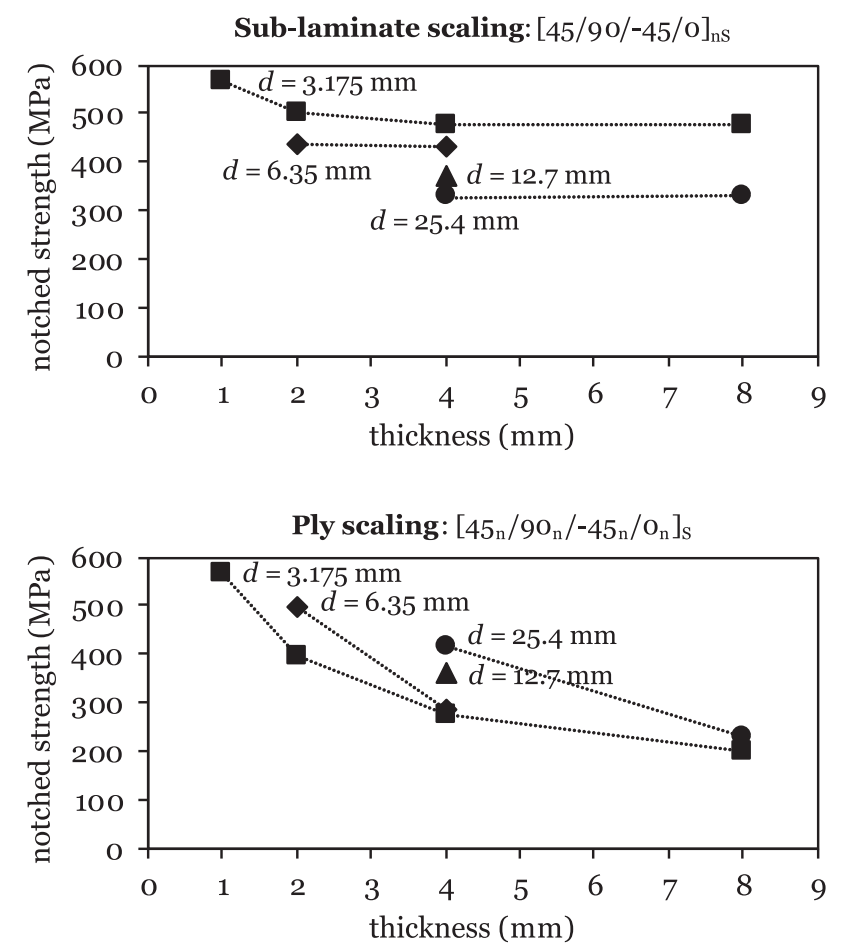

Figure 22: Effect of laminate thickness on the notched tensile strengths of IM7/8552 carbon/epoxy coupons with different hole diameters $d$ (after Wisnom et al. [50]). 

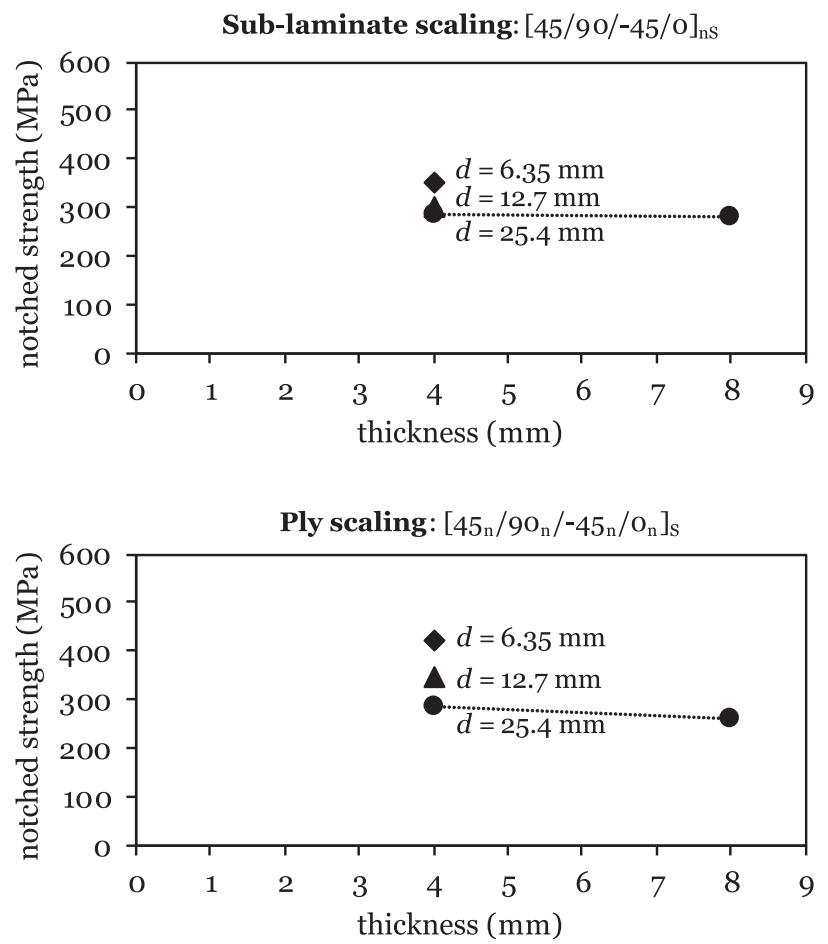

Figure 23: Effect of laminate thickness on the notched compressive strengths of IM7/8552 carbon/epoxy coupons with different hole diameters $d$ exhibiting valid failure mode (after Wisnom et al. [50]).

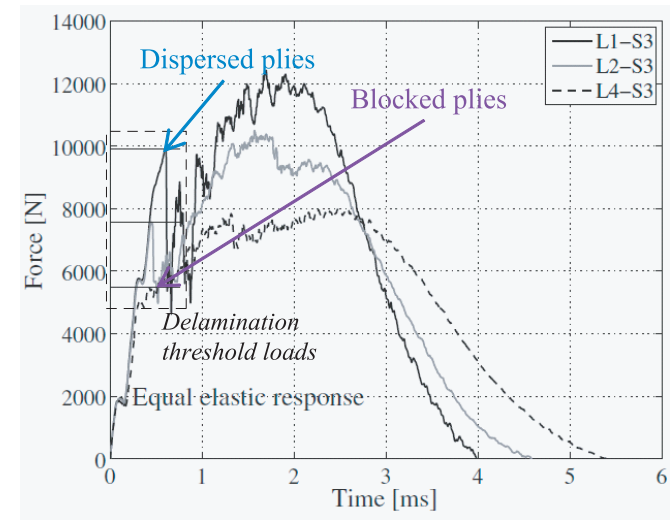

Figure 24: Impact response of laminates with different degrees of ply blocking (after González et al. [54]). 


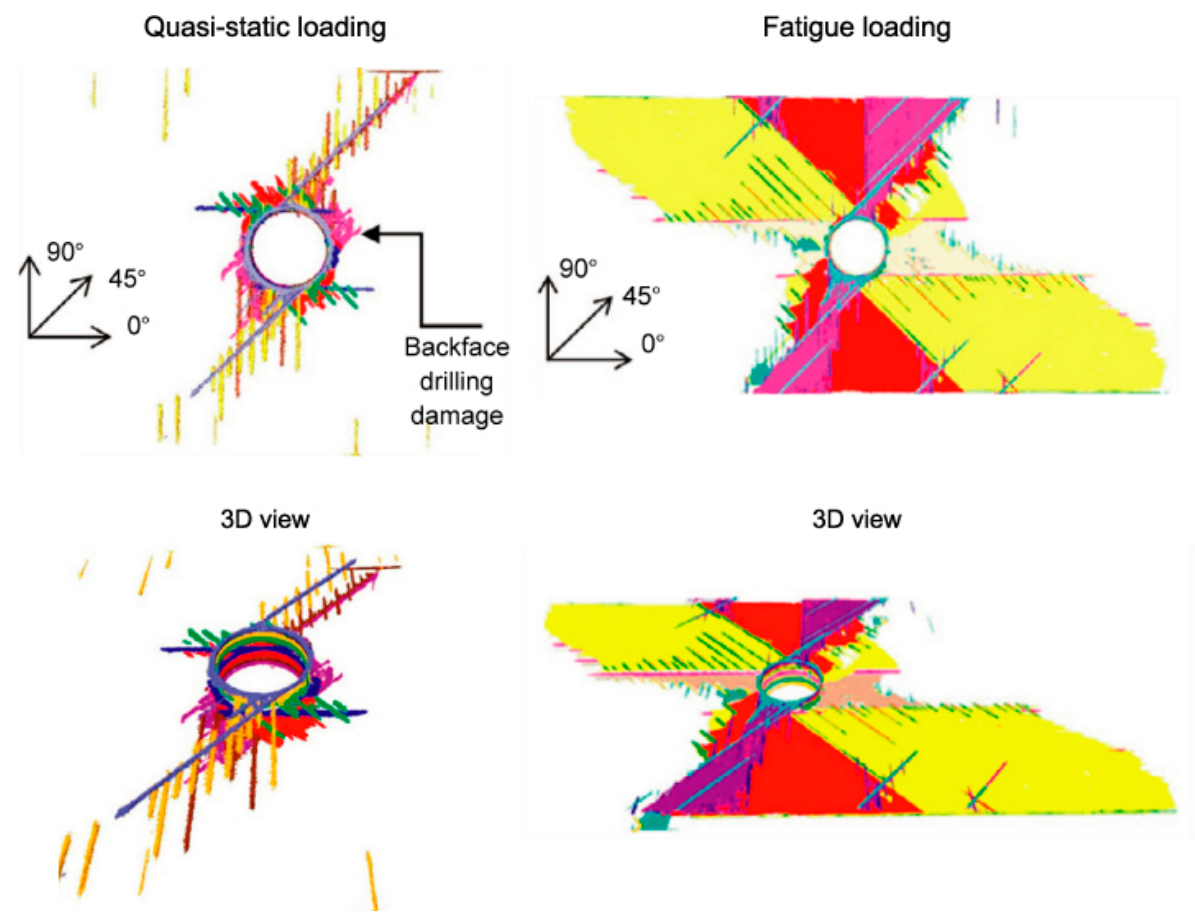

Figure 25: X-ray computed tomography images of interrupted quasi-static and fatigue openhole tension tests (after Nixon-Pearson et al. [61]).

Thin ply

$\left[45 / 0_{2} /-45 / 90 / 45 / 0_{2} / 45 / 0\right]_{55}$

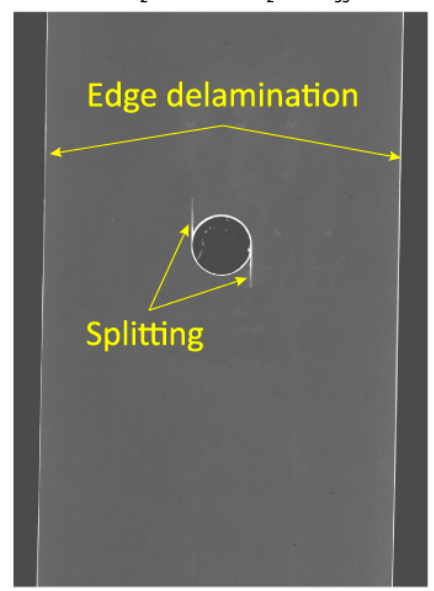

Thick ply

$\left[45_{5} / 0_{10} /-45_{5} / 90_{5} / 45_{5} / 0_{10} / 45_{5} / 0_{5}\right]_{5}$

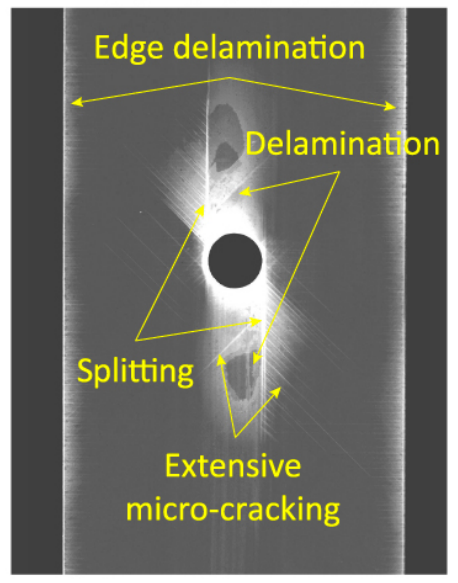

Figure 26: X-ray pictures of specimens subjected to tensile fatigue loading at room temperature, after 73,000 cycles, with a ply thickness of $0.04 \mathrm{~mm}$ and a total laminate thickness of $3.2 \mathrm{~mm}$ (after Sihn et al. [28]). 


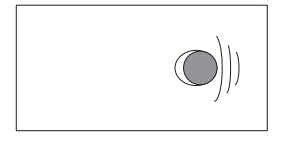

Bearing

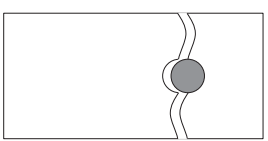

Net-tension

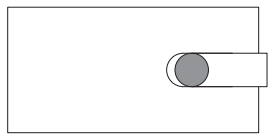

Shear-out

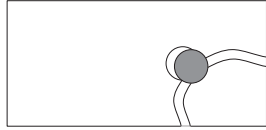

Cleavage

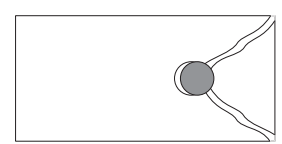

Tear-out

Figure 27: Joint failure modes (after ASTM D5961/D5961M - 13 [164]).

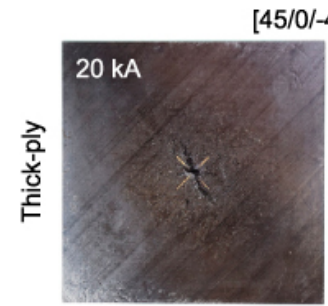

$[45 / 0 /-45 / 90]_{6 s}$

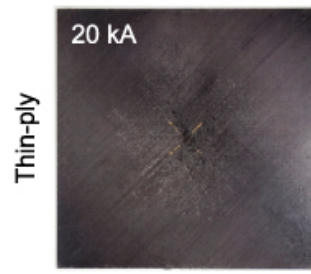

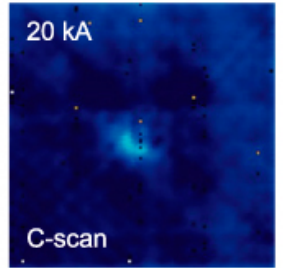

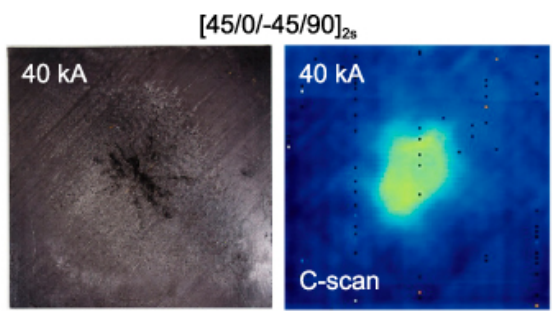

$[45 / 0 /-45 / 90]_{6 s}$

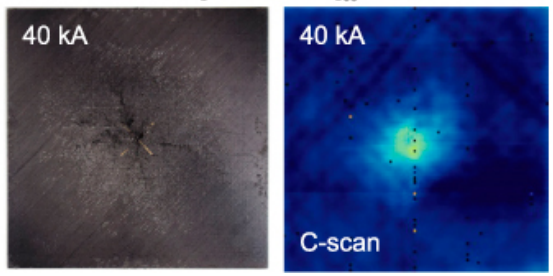

Figure 28: Visual and ultrasonic C-scan images of carbon fibre-reinforced thermoplastic laminates subjected to lightning strikes (after Yamashita et al. [64]). 


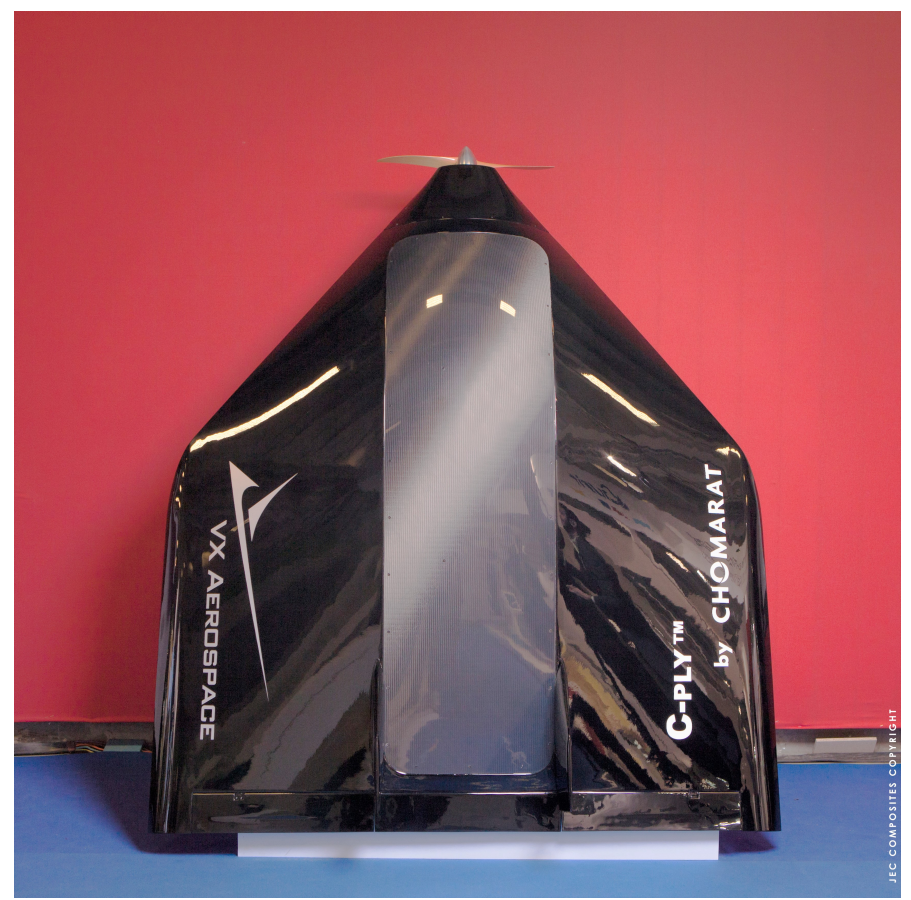

Figure 29: Excellent surface appearance of thin-ply non-crimp fabrics. Courtesy of Chomarat (C)Laurent Becot Ruiz.
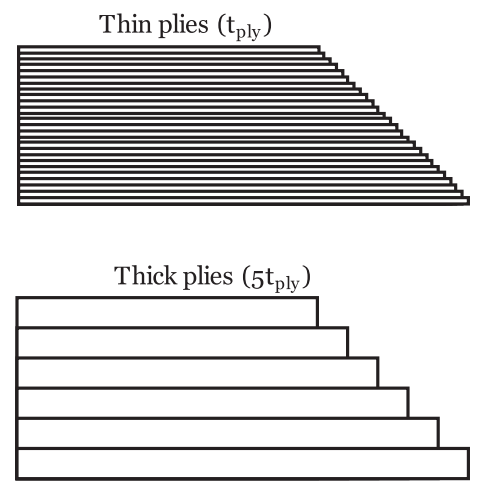

Figure 30: Illustration of ply drops with thin and thick plies. 